\title{
EL DIEZMO EN LA RIOJA (XVI-XVIII)
}

\section{Santiago Ibáñez Rodríguez*}

RESUMEN. A partir de un exhaustivo estudio de la documentación eclesiástica se analiza una de las más importantes exacciones feudales del Antiguo Régimen: el diezmo. Más que presentarlo como una fuente fiable para estudios económicos, el autor penetra en el enmarañado mundo de las relaciones que el diezmo establecía, configurándolo como elemento social diferenciador y mostrando toda su riqueza y diversidad.

RESUME. A partir d'une étude exhaustive de la documentation ecclésiastique est analysée l'un des plus importants prélèvements féodaux de l'Ancien Régime: la dîme. L'auteur ne se contente pas de la présenter comme une source fiable d'études économiques, mais pénetre un sein du monde complexe des relations que la dîme établissait, la faisant apparaître comme un élément social, differenciateur et montrant toute sa richesse et toute sa diversité.

El diezmo era un impuesto de naturaleza feudal, percibido mayoritariamente por la Iglesia. Gravaba en torno al $10 \%$ de la producción agropecuaria bruta y estaba destinado al mantenimiento de los ministros de la religión y del culto divino.

No siempre, como veremos, era la Iglesia su perceptora y, cuando lo era, no todo iba a los fines citados. Con frecuencia se recaudaba como una más de las rentas feudales, arrendándose conjuntamente al mejor postor, de ahí que cuando se pretendió abolir se consideró como un impuesto feudal ${ }^{1}$. Es decir, que más que un mandamiento divino de obligado cumplimiento para los cristianos - como lo definían las

\footnotetext{
* Doctor en Filosofía y Letras, Historia Moderna. Artículo entregado el 28 de junio de 1991.

Agradezco la colaboración de N. Armas Lerena, J.L. Gómez Urdáñez, M. Ruiz de Ocáriz.

1. CANALES, E. 1985: 245-274. Del mismo, 1982. pp. 105-187. Sobre el diezmo como exacción feudal ver GOUBERT, P. 1984: 13-32. M. Artola considera que «expropiación eclesiástica y abolición de los diez-
} 
Constituciones Sinodales-, era una detracción sobre el producto agrario sin derechos de propiedad ni contraprestaciones que lo justificasen, por lo tanto, una exacción feudal más.

Por estos motivos, a partir de la segunda mitad del siglo XVIII, el diezmo fue considerado como un tributo más que favorecía la riqueza pública y no sólo a la Iglesia y, por tanto, era el que permitía mantener al clero, sostener el culto, socorrer a los pobres, aliviar las necesidades en tiempo de calamidad y ser un asidero de la tierra o el rey cuando lo reclamasen'2.

Para la iglesia la obligatoriedad de pagar el diezmo residía en que éste tenía su origen en el derecho divino y natural, era de carácter universal (lo debían pagar todos los cristianos), voluntario (para el sustento del clero y el culto), gracioso (agradecimiento a Dios de los frutos anuales) y obligatorio para todos los creyentes pues toda infracción conllevaba a pecado mortal, además de ser duramente castigada para evitar precedentes y mantener la propiedad y la posesión del derecho3.

El diezmo gravaba todos los productos de la agricultura y de la ganadería, en menor medida, la pesca y, en algunos casos, la producción artesanal y los salarios ${ }^{4}$.

En La Rioja, como en el resto de España, se diezmaba de los cereales básicos (trigo, cebada, centeno y avena) con sus diversas variedades (trigo blanco, álaga, valenciano, hembrilla, "casquijo", "granzas", morcazo, tranquillón, escanda, alcaceres, etc.). De las legumbres, sobre todo, habas ("buenas", "duras", "cucheas") y alubias, aunque también arvejas ("cuadradas" y "redondas"), garbanzos, lentejas. Se diezmaba vino (tanto como uva o como mosto o vino tinto o ribadavia), vinazas e incluso de las uvas de las parras; de la oliva, de los huesos de oliva ${ }^{5}$; de los frutos secos (nueces, almendras); de la fruta (melocotón, pera, manzana, membrillo, limón). De todo tipo de producto hortícola (ajos, cebollas, zanahorias, puerros y nabos). De la hilaza (lino, cáñamo), de la seda, la morera, el cardón; la hierba para el ganado, de los yeros $^{6}$, alholvas y ricas. De todas las crías de los animales (corderos, chamaritos, cabritos, terneros, potros), de los animales de casa (pollos, ocas, patos, ansarones,

mos son manifestaciones de la misma realidad socioeconómica: la desaparición de la iglesia-propietaria señorial, desarboladura del poder político tradicional del estamento eclesiástico y uno de los puntos más importantes en la sustitución del antiguo régimen por el nuevo orden burgués», ARTOLA GALLEGO, M. 1978: 128 y ss.

2. CANGA ARGÜELLES, J., 1833: 349.

3. ÁLVAREZ VÁZQUEZ, J.A. 1984: p. 45. MARTÍN RODRÍGUEZ, J.L. 1975: 70-71. CANALES, E. 1982. C.S., 1700: 470.

4. Los diezmos sobre los salarios existían en Nestar o Salinas de Pisuerga (diócesis de Palencia) y contribuían con un real de cada veinte ganados; MARCOS MARTíN, A. 1983: 105; estos diezmos fueron abolidos por las Cortes en 1814 aunque todavía subsistían en algunos puntos en 1836.

5. Archivo de la Catedral de Calahorra [en adelante A.C.C.] Libros de Tercio. En 1686 le correspondieron al Obispo 4 fns. de huesos de oliva, que a razón de 8 rs. la fanega le suponen 32 rs.

6. Más frecuentemente en Matute, Clavijo y Alberite. 
lechones, conejos). De la lana, los quesos y requesones. De las colmenas (cera, miel). Y de las patatas y el maíz cuando comenzaron a producirse.

Este principio general variaba según los lugares e incluso de una parroquia a otra aún cuando se encontrasen dentro del mismo obispado: los vecinos de Pedroso quedaron exentos de pagar diezmo de pollos, peras, melocotones, puerros y cebollas a las tercias del Obispo a partir de 1562. Y unos años antes, en 1549, el deán, dignidades, canónigos, rectores, beneficiados y universidad de Logroño ganaron demanda al Concejo, justicia, regidores y vecinos de la ciudad de Logroño para que diezmasen de seda, morales, fruta, hortaliza (ajos, cebollas, puerros, nabos, canarias y melones), almendras, nueces, olivas y parras?.

En Casalarreina, Briñas, Abalos, San Vicente y otros se diezmaba miel, cera y lana mientras que los vecinos de Logroño estaban exentos de contribuir de ello desde siempre. En Quel no se entregaba ni vacuno ni diezmo de colmenas; en Alberite ni lana ni pollos, en Albelda lana, en Agoncillo ni olivas, ni aceite ni lana y en Cidamón no diezmaba el vino ${ }^{8}$.

La norma común era que de los cereales principales (generalmente denominados "diezmos mayores") y del vino (donde se producía), siempre se diezmase. Y que de las especies de cultivo secundario, o de implantación tardía, o bien se diezmaban en especie, más frecuentemente en dinero o, sencillamente, estaban exentos de contribuir con la décima parte. En cualquiera de estos tres casos se encontraban, según los lugares, las hortalizas, frutales, plantas industriales, forrajes, patatas y algunas leguminosas. El ganado también diezmaba, aunque existían muchos lugares donde estaba exento. Los animales de corral (aves y ganado menudo) acostumbraban a no pagar diezmo o si lo hacían, generalmente, era en dinero.

Las diferencias que existían entre una villa y otra respecto a los productos que diezmaban eran debidas más al momento en el que comenzaron a diezmar y, en qué condiciones lo hicieron, que en cuanto al número de los productos que debían diezmar. Está claro que allí donde no se producía un determinado fruto no se diezmaba, aunque ello en ningún caso significase que no se diezmaría si se cultivase. En cambio, la variedad de productos que debían diezmar venía determinada por la producción, su cuantía y su importancia en la economía local de cada dezmería. Veamos algunos ejemplos.

Mientras que el vino de Arrúbal, Agoncillo y San Martín de Berberana se incluyó en los menuceles hasta bien entrado el siglo XVIII y, por lo tanto, en muchos caso se pagaba en dinero, en Fuenmayor, como en la mayor parte de las localidades riojanas del valle, era uno de los diezmos mayores desde siempre.

7. Pedroso: A.C.C. leg. 2.001. Según Concordia con el Obispo. Logroño: Archivo Parroquial de la Imperial de Santa María de Palacio de Logroño [en adelante A.P.Pal.] c. (caja) 82, nº 43 (1549).

8. En A.P.Pal. c. 82, $\mathrm{n}^{\circ} 43$ (1549). Archivo Histórico Provincial de Logroño [en adelante A.H.P.Lo.] Catastro, Lbs. (Libros) 3, 19, 20, 224 y 553. 
La proliferación de "conexos caseros", los numerosos quesos y requesones que se hacían, así como las muchas colmenas que existían en Casalarreina a finales del siglo XVII estimuló a los beneficiados de la villa a exigir su diezmo. Los vecinos alegaron que jamás habían diezmado en la villa de semejantes especies, por cuya razón creían estar exentos de esa contribución. De nada les sirvieron todas las alegaciones que hicieron: el Cabildo de la villa, después de dirigirse al Obispo para que los respaldase, publicó notificaciones nominales de quiénes no cumplían con el diezmo y precisó todos los incumplimientos que se hacían en la villa con el diezmo. Además de acusarles de no querer pagar diezmo de conejos, quesos, requesones y miel, les recriminó de ser malos diezmadores del "ganado ovejuno y cabrío", de querer engañar a los clérigos con el diezmo de las huertas al no entregarlo en especie. Añadían que "debiendo pagar todos los diezmos de Pan y Vino y demás granos, legumbres, frutas, hortalizas, lino, lana y cáñamo y otros cualquiera genero y especie de frutos no lo hacen". Al final, la villa tuvo que pagar diezmo de todo lo enumerado y, además, de cerdos, yeros, hierba y alholvas?.

La introducción de nuevos cultivos, como la patata y el maíz, y su contribución al diezmo trajo múltiples contrariedades que en 1698 por medio de sentencia Sinodal se quisieron solventar. Pero incluso a finales del XVIII, cuando estos cultivos ya estaban totalmente implantados en La Rioja y su producción era de cierta importancia, se dieron numerosos pleitos y sentencias para que de ellos se pagase el diezmo ${ }^{10}$.

El porcentaje que el diezmo representaba del total de cada uno de los productos era variable. Lo más corriente estaba en torno al $10 \%$. Contribuían con esa tasa sobre todo los diezmos mayores y tendían a ser más bajos (variando situaciones y lugares) aquellos productos secundarios o de auge reciente (diezmos menores, minucias y ganado) dándose la circunstancia de que estos productos se pagaban regularmente en dinero ${ }^{11}$.

Hay que señalar que era frecuente encontrar heredades que no diezmaban o, si lo hacían, el porcentaje era inferior a la décima parte. Esto ocurría con ciertás propiedades de algún convento, iglesia o monasterio que bien podían dar 1/40 si las labraban directamente o 1/20 si las daban en arriendo. Así, por ejemplo, el hospicio de la Orden de San Juan, con casa en Logroño, fue obligado a diezmar de las heredades que había comprado en Agoncillo y Villamediana pero no de diez partes una, sino que en algunas fincas lo podía hacer de trece una ${ }^{12}$.

9. Archivo Histórico Diocesano de Logroño [en adelante A.H.D.Lo.] c. 19, 1696. Esta regulación de nuevos diezmos en Casalarreina coincide en el tiempo con el cargo de Beneficiado Entero y Decano del Cabildo de D. Francisco Vélez Vergasa, Consultor del Santo Oficio de la Inquisición de Navarra, Abogado de los Reales Consejos y Fiscal por su Majestad de su Real Regalía de Casa de Aposento.

10. C.S., 1700, p. 471. En Alberite se dió pleito para que se diezmase de maíz en 1767 y de patatas en 1799. A.C.C. Libros de tazmías.

11. Las variaciones regionales son muy marcadas: de la entrega del 10\% de toda la producción de Galicia, las dos mesetas y Asturias a la disparidad de porcentaje en el País Catalán, Valencia y Murcia o en Francia. CANALES, E. 1985: 247-248.

12. A.C.C. Lb. 233, f. 443. Igualmente ocurría con la Compañía de Jesús de Logroño en el término de Atayo, Archivo Parroquial de la Colegial de Logroño y Albelda [en adelante A.P.Red.] nº 2.141 (concordia de 29-IV-1651 con la Redonda de Logr.) y con otras muchas instituciones como veremos. 


\section{Modo DE DIEZMAR}

El diezmo podía ser entregado mientras se realizaba la cosecha. Directamente de lo amontonado en las eras o llevando cada labrador su parte a la cilla u hórreo ${ }^{13}$.

Aunque todas las tierras debían diezmar no siempre estaba claro de qué modo debían hacerlo por lo que, ante la duda, se tomaba como referencia a la persona que labraba las tierras y su residencia. Cada parroquia poseía su cilla u hórreo y su campanil configuraba un dezmatorio alrededor de su pila. Los parroquianos que residían en esa villa entregaban la décima parte de la cosecha. Los que residían en la población y cultivaban tierras en otros dezmatorios anejos al suyo, daban la veintava parte. Las heredades cultivadas por colonos también diezmaban 1/10 aunque el propietario fuese parroquiano de otra iglesia y siempre y cuando la reja saliese de la villa. Cuando un vecino cultivaba tierras en una tercera villa, es decir que había trasunto de jurisdicción o trasumo, o labraba en una segunda parroquia pero no salía la reja de su casa o salía pero no tornaba ese día a casa, el diezmo que se producía era de la parroquia donde estaban situadas las posesiones ${ }^{14}$.

Aunque las sinodales detallaban claramente todos los pormenores, la propia complejidad del sistema dezmatorio posibilitaba todo tipo de fraude y engaño. Los propios interesados no sabían, en muchos caso, a qué atenerse para percibir sus diezmos. Por ejemplo, en Casalarreina, en 1799, el mayordomo manifestaba su perplejidad ante la imposibilidad de percibir los diezmos que el Monasterio de San Millán causaba en su dezmatorio y se quejaba de que este asunto le enfrentase tanto con el Monasterio como con los Cabildos de Cihuri y Zarratón ${ }^{15}$.

La casuística que envolvía al sistema de diezmación enmarañaba el proceso aún más, si cabe, cuando existían tierras que por cualquier causa tenían ciertos privilegios a la hora de diezmar. Esto ocurría con las tierras de algunos cabildos, instituciones religiosas, el Obispo u otras. Así muchos clérigos de orden de Sacro (de Ordenes Menores o de origen Patrimonial) no diezmaban de sus bienes patrimoniales, ni de otros que arrendaban de otras personas al hórreo común diciendo que los dichos bienes patrimoniales se los dieron sus padres u otras personas por título de patrimonio para así poderse ordenar; y que de los que arriendan y compran no son obligados a los dezmar al dicho hórreo común. Además estaban las tierras de anejos:

«So color de anexos de los Arcedianos y tributos de aniversarios y capellanías — decían las Sinodales-, se han introducido en este Obispado muchas maneras de dezmar, de suerte que ya los diezmos principales están notablemente disminuidos» ${ }^{16}$.

A pesar de la ilegalidad, en los contratos de compra/venta de tierras se comercializaba con la propiedad del diezmo (como más adelante veremos) por lo que

13. Ver C.S., 1700: 470-472.

14. Ver C.S., 1602, f. 81.

15. A.H.D.Lo. c. 19, Libro de tazmía, 1799.

16. C.S., 1602 , f. 84. 
las Constituciones Sinodales debían reiteradamente precisar que si alguna Iglesia, Cabildo o cualquier otra Institución Eclesiástica, compraba alguna heredad se adquiría totalmente la propiedad del suelo y fundo de la heredad y no el derecho de percibir el Diezmo de ella porque este ha de quedar afecto, como antes estaba, a la parroquialidad y, este Diezmo, ha de entrar, como de antes, en el hórreo común de aquella Iglesia, siendo partible entre todos los interesado que antes solían percibirlo ${ }^{17}$.

Una vez aclarado qué tierras eran diezmeras de cada cilla se planteaba el problema de cómo debían diezmar cada uno de los frutos que se cogían en ellas. La norma general era entregar los diezmos en especie. Así lo hacían con los cereales, el vino y cualquier otro producto cuya cantidad fuese estimable. Pero esos mismos frutos si se recogían en cantidades mínimas, eran raros o de difícil cuantificación, se diezmaba en dinero.

Los individuos que cultivaban y tenían morales y moredas en Logroño sólo debían diezmar cuando vendían la hoja y debían hacerlo del dinero que obtuviesen de la venta, es decir, "de diez maravedís uno". Quien "criase seda" con la hoja de sus propios morales y moredas o, si para criar, compraba la hoja de otras personas...

«...que sean obligados a pagar y paguen a su parrochia el diezmo de quince capullos o de quince pejos o medidas de capullos uno, con tanto que el que vendiere la hoja pague al que la compró el diezmo del precio que conforme al capítulo de arriba habrá de pagar a su parrochia de manera que no aya más de un diezmo y éste pague siempre el que criare la seda de quince capullos o de quince medidas o pejos de capullos uno. Y si el comprador y el que vende la hoja son parrochianos de diversas iglesias, el que pagare el diezmo de los dichos capullos lo de y pague por mitad entre las dichas dos iglesias conforme a la costumbre de la dicha ciudad cobrando del que vendió la hoja el diezmo del precio por que se la vendió» ${ }^{18}$.

En el mismo Logroño el diezmo de fruta y el de la hortaliza eran diferentes según se cosechase en las tierras catalogadas como huertas o fuera de ellas. El diezmo de la hortaliza variaba según de qué producto se tratase. Esto era así porque se había establecido qué heredades eran consideradas "huertas" de la ciudad y por tanto adscritas a "diezmo de huertas"19. La fruta pagaba diezmo solamente cuando se vendía, con excepción de cuando lo hacían sus dueños "por menudo para bastimento y provisión de la dicha ciudad" y cuando se consumía por sus propietarios en su casa o daban, prestaban o "presentaban" y, en ningún caso, lo producido en las huertas. La hortaliza, entiéndase, los ajos, cebollas, puerros, nabos, canarias (zanahorias) y melones, debían diezmar 1/10 de lo que se vendía "por junto o por menudo" y no de lo que era para autoconsumo o se regalase. De las berzas se debía entregar el diezmo de las que se plantasen "en piezas si se vendieren por junto o por menudo y no de las

17. C.S., $1700: 479-481$.

18. A.P.Pal. c. $82, n^{\circ} 43$ (1549).

19. Las citadas en Archivo Parroquial de Santiago el Real de Logroño [en adelante A.P.Sant.] leg. (legajo) $3, n^{\circ} 39$. 
que se plantaren en las huertas aunque se venda". Del resto de la hortaliza solamente se debía el diezmo de aquello que se "vendiere por junto"

Este procedimiento tan plural de diezmación, que diferenciaba productos y tierras en las que se cosechaban, fue, en muchos, casos origen de conflictos máxime cuando el número de huertas aumentó con el transcurso del tiempo. En 5 de marzo de 1674 la Colegial de Logroño obtuvo sentencia a su favor por la que podía exigir el diezmo a varios vecinos y parroquianos de la Redonda que en un principio se negaron y después demoraron el diezmar de pan y vino y de las hortalizas que cogían ${ }^{21}$. Al frente de los vecinos estaban Joseph de Santa María, Francisco Galbete, D. Ignacio de Vicio Ponce de León y D. Joseph de la Vid, Tesorero y Rector del Santo Oficio quienes notificaron al Cabildo lo complejo del sistema de diezmo de las huertas, que discriminaba unas de otras, más aún cuando se tenían "huertas, piezas o fruta" en arrendamiento y se pagaba en proporción $1 / 10$ a la renta o cuando el diezmo tocaba a las "cédulas, curatos, aniversarios" u otros.

La Redonda instigó a sus parroquianos a pagar el diezmo. Les acusó de que "si algunos hortelanos no han diezmado en esta forma ha sido sin ciencia, paciencia y sabiduría", y que "de la heredad que tiene D. Joseph de Lavid, uno de los que litigan, se a diezmado a mis partes de todas las especies de hortalizas". Estos insistieron en lo discriminatorio del "apartado 6" (el referente a los diezmos de huertas) a lo que Francisco de la Plaza, en nombre del Cabildo, alegó que

«es de advertir que no quedan exceptuadas todas las huertas, sino las que eran de recreación y que sus dueños no hacen granjería de ellas».

Pero los vecinos insistieron en que se excedían con el término "recreación" y que tales heredades eran "xardines", a lo que respondió el Cabildo de la Redonda con una sentencia de "excomunión mayor" contra ellos ${ }^{22}$. Al final tal sentencia no llegó a mayores y los vecinos tuvieron que acceder a entregar los diezmos que hasta entonces retenían, además de acceder al sistema de huertas especiales de diezmo.

Mayores problemas acarreaba el diezmo del ganado. En cada villa se establecían normas diferentes según el ganado fuese estante o trashumante. En el primer caso se seguían normas idénticas a como se hacía con los demás frutos. En el segundo se producían todo tipo de variantes por lo que se daba por buena la norma de cada villa o lugar. Para todos los casos se establecía era que los animales se diezmasen cuando se

20. A.P.Pal. c. $82, \mathrm{n}^{\circ} 43(1549)$.

21. A.P.Red. $\mathrm{n}^{\circ} 2.640$ (5-III-1674). En tales pleitos se hace referencia a una Concordia de 12-XII-1581 que no es otra que la Sentencia de 9 de julio de 1549 (A.P.Pal. c. 82, $\mathrm{n}^{\circ} 43$ ).

22. A.P.Red. $n^{\circ} 2.644$ (14-IV-1674). Letras del Cabildo de la Colegial contra Marcos de Argutia, Andrés de San Juan, Juan de Gómez, Juan de Funes, Joseph Díaz, Francisco de Leza, Domingo de Leza Menor, Juan de Carra, Pedro López, Antonio Carpintero, Diego Tejada, Manuel Gil, Mateo Izquierdo y otros que llegan hasta 27 nombres "vecinos de la Ciudad y personas que tienen Huerta y heredades... que deven dezmar de Pan y Vino y otras Semillas y de hortaliza que cogen de todo genero de diez Uno de otros frutos y no lo hacen aunque se les a notificado letras censuras en Virtud de auto del Señor Provisor de este obispado para que los susodichos diezmen" o podrán ser excomulgados. 
pudiesen aprovechar, para evitar que se entregasen muy pequeños, recién nacidos o enfermos y no fuesen de ninguna utilidad para sus perceptores ${ }^{23}$.

Los ganados de una localidad, si se apacentaban en otra villa sin pagar por ello, debían diezmar en la cilla de donde procedían y vivía su propietario. Si el amo del ganado vivía en un lugar y, el ganado estaba en otro donde pasaba día y noche o pacía en un comunero sin pagar renta, se debía entregar el diezmo por mitad. Si pacían en un lugar pagando por ello, o con licencia del señor del lugar, se debía dar el diezmo por mitad o prorrata del tiempo que habían estado en cada sitio. Cuando pacían en un lugar y parían en otro o parían en un tercero también se debía hacer prorrata del diezmo entre los tres lugares ${ }^{24}$.

Los ganados que iban a Extremadura y Andalucía y hacían el verano y estío en La Rioja debían diezmar prorrata de todos los diezmos que hubiese al tiempo de diezmar "y que no cumplan con decir que los señalaron en Extremo, o que se han muerto" o que diezmaron en el camino. Se especificaba que los dueños de ganados que llevan a pastarlos a Extremadura o Andalucía a dehesas "privilegiadas de Diezmo" debían diezmar a las parroquias de donde son sus diezmos aunque ya hayan dado en diezmo en el "extremo" por razón de privilegio, pues estos diezmos tan solo eran los que se devengan de esos privilegios ${ }^{25}$.

Una vez que se establecía cómo y qué ganados debían diezmar, se especificaba la manera de elegir los que correspondiesen para el diezmo. Se debía hacer a "porti1lo", es decir, a suerte y no a "elección o garra" ${ }^{26}$. En Casalarreina donde no existían grandes rebaños se establecía su valor en dinero de esta manera:

«En este año de 1780, siendo mayordomo D. Faustino Francisco Salazar de Gurendez, Beneficiado en la parroquial de San Martín de Casalarreina, como también de los chivos, que según costumbre se han dezmado a medio real por cada uno, por no haber sujeto que llegue a numero decimable en especie la porción, que pueda criar, y por la misma razón han dezmado a real por cordero los que no tienen rebaño sino alguna que otra oveja. Téngase presente que los que tienen rebaño, por costumbre, en no llegando a dicho numero, lo que según tasación, valga medio cordero; pero también aunque no lleguen a diez, sino son menos que siete los que tuvieren tienen que dezmar un cordero. Pónese con distinción los dezmeros, los corderos dezmados en especie por los ganaderos y los dezmados en dinero por los los que no lo son, como así bien los chivos dezmados por unos y otros en dinero» ${ }^{27}$.

El diezmo podía ser recogido en las propias heredades o ser llevado al hórreo por los diezmantes. En La Rioja se dejó de entregar el diezmo en las propias fincas donde se cosechaba a finales del XVI o incluso antes y, aunque no podemos precisar más sobre las fechas, lo cierto es que para comienzos del XVII ya no se encuentra ningu-

23. Sentencia de D. Diego de Zúñiga dada en 1410 y recogida por la C.S., 1602, f. 81. Sentencia de D. Alonso de Castilla, 1539, recogida por la C.S., 1602, f. 82.

24. Sentencia de D. Diego de Zúñiga dada en 1410 y recogida por la C.S., 1602, f. 81.

25. Ver. C.S., 1602, f. 81. C.S., 1700: 475.

26. C.S., 1602, f. 82. Así se hacía en Ausejo A.C.C. Lb. 265, Ausejo (1764 y 1728), fs. 3 y ss.

27. A.H.D.Lo. c. 18 , Libro de tazmías y repartos, 1780. 
na constancia documental. Diezmar de esa manera suponía que los cereales se entregasen en haces, es decir, espiga y paja; que tuviesen que ser recogidos por sus beneficiarios en las propias heredades. Los preceptores tenían que contratar a varios recogedores para que, en época de recolección, anduviesen los campos, controlando la cuantía de la producción y determinar cuál era su diezmo ${ }^{28}$.

La uva muy rara vez era "abandonada" en el campo y generalmente se llevaba a los lagos por los propios labradores a cambio de una remuneración:

«dejaban en cada carga montón o montones de mies que tocaba de su diezmo al dicho Cabildo General un ramo verde indicando y por esta señal los recogedores de dicho diezmo lo traigan y llevaban a su hórreo y hórreos y en lo que tocaba a la uva la dejaban vendimiada en una cebada o parte de la viña donde cogían el fruto y otras muchas veces algunos traían el diezmo del hórreo del Cabildo General pagándoles su trabajo» ${ }^{29}$.

A partir del siglo XVII lo normal fue que el labrador cosechase, trillase y aventase los granos por su cuenta y, con el grano limpio de "polvo y paja", contribuyese con la décima parte de las pilas de granos que se amontonaban en las eras. Que fuese el propio labrador quien llevase los granos al hórreo de los diezmos, generalmente situado en las propias eras o en sus lindes, o de ello se encargaran los recogedores, puestos por los interesados del diezmo, era algo que variaba de una villa a otra.

La costumbre de que los diezmantes llevasen la décima parte de su cosecha al acervo común estaba muy extendida y en ningún caso era gratuita. Lo normal era que por esa práctica los labradores, o el concejo o la villa en general, recibían un pago en metálico o una pitanza:

«este pan lo diezman y primician en rama dejando en las heredades en haces el diezmo y la primicia y por evitar esto se concertó con ellos [los labradores] el Deán y Cabildo lo limpiasen y en grano limpio lo pusiesen en una casa y por esto se les da a dos Rs. de cada fanega de todo pan y cada señor prebendado paga las fanegas que le tocan» ${ }^{30}$.

En Albelda el grano y la uva debían llevarse después de limpios al hórreo de la iglesia a cambio de "la colación de pan y vino y queso que son obligados el día tercero de Pascua de Resurrección" que ofrecía la Colegial de Albelda y Logroño a los vecinos, concejo y justicia ${ }^{31}$. En otros lugares, como en el dezmatorio de Palazuelos, se beneficiaba, no el común de la villa, sino el labrador que llevaba los diezmos: por fanega de pan que llevaba al hórreo cada cultivador se le pagaban dos reales ${ }^{32}$.

28. Ver A.P.Sant. leg. 2, f. 38, traslado de 1798 de un documento de 1624.

29. A.P.Sant. leg. 2, f. 38, traslado de 1798 de un documento de 1624.

30. A.P.Red. $\mathrm{n}^{\circ}$ 1.854. Es el ejemplo de los diezmantes del término de Atayo (Lardero) con la Redonda de Logroño.

31 A.P.Red. $n^{\circ} 2.084$ En 3-VII-1648 el Cabildo de la Colegial y Albelda ganaron pleito contra los vecinos de Albelda por el que se seguía la costumbre de llevar los propios vecinos los diezmos al hórreo pues «se jactaban que les han de dejar [a los beneficiados] los diezmos en las piezas como se siegan».

32. A.P.Red. $n^{\circ} 1.854$. 
Con el transcurrir del tiempo las contraprestaciones en especie se cambiaron, en la mayoría de los casos, en pagos en metálico. En Alberite la iglesia de Palacio de Logroño y la Catedral de Calahorra debían dar a los vecinos de la villa, el día de las ánimas, dos corderos como colación; a los alcaldes, sacristán y curados, una comida el día de Santo Domingo por entregar el diezmo en el hórreo. Las divergencias que se suscitaron entre las partes propiciaron que a partir de 1641, se transformasen esas gratificaciones en un pago en metálico: 422 reales anuales a pagar por los interesados en el diezmo según la parte que se llevasen ${ }^{33}$.

En Casalarreina el que transportasen los vecinos y feligreses el grano desde las eras a las dependencias donde se recogían y el vino a los lagos y tinas era una costumbre inmemorial por la que el Cabildo pagaba a la villa 288 reales al año. Aunque no por ello dejaron de seguirse numerosas incertidumbres para los beneficiados. Los labradores, en muchas ocasiones, esperaban a llevar su diezmo el último día, el día del reparto, o incluso lo hacían con posterioridad, con lo que el tiempo de las distribuciones se alargaba enormemente en detrimento de sus interesados. En 1698 se dieron notificaciones y censuras desde Calahorra para impedir tales abusos ${ }^{34}$.

Los vecinos se exculparon de que no se cumpliese con la tradición por culpa del mayordomo, quien, en el tiempo de la recogida de los granos no se encontraba cumpliendo con sus obligaciones:

«y p. que si algunas ocasiones se han dejado de llevar los frutos pertenecientes a el diezmo a dicho hórreo y llevándolos dichos vecinos a sus casas no a sido por dejar de haber cumplido con lo que son obligados sino por estar cerrada la puerta de dicho hórreo y no haber en el persona alguna que lo abra ni Recoja».

También...

«que por hallar cerrado el dicho hórreo y sin persona alguna dichos vecinos son molestados con perjuicio irreparable de gran decencia(?) obligándoles a tocar la campana repetidas veces para que vengan a recibir los diezmos»

y las veces que faltaba el mayordomo, y se les abría la puerta, les asistía su criada por lo que nadie asienta lo diezmado ${ }^{35}$. Al finalizar los pleitos que se siguieron, se concluyó que la costumbre era una obligación adquirida por sus antepasados y, que para poner remedio a la dejación del mayordomo, se le obligaba a asistir "todos los días personalmente en dicho Acerbo por Mañana y tarde, desde que se empieza a trillar asta que se fenezca el recoger dichos frutos" o, en su defecto, durante cuatro

33. A.C.C. Lb. 265 , fs. 17 y ss.

34. «Que desde el día de la publicación de estas letras en adelante y llegando el caso de recoger los frutos de pan diezmen a el Cabildo y Beneficiados de la dicha Villa y a su hórreo común lo que corresponde a los dichos frutos desde las eras donde se trillan y se recogen sin excusa alguna», A.H.D.Lo. c. 19, 1698.

35. En otros lugares, como Albelda, los que cerraban las puertas con candado eran los alcaldes de las villas para pner de manifiesto su disconformidad con el reparto de la primicia: «por orden de los Alcaldes de dicha Villa se había puesto un candado en la puerta», A.P.Red. $n^{\circ} 2.472$. 
meses. En caso de faltar el mayordomo cuando los vecinos fueran, éstos podían llevarse sus diezmos a casa sin perjuicio alguno ${ }^{36}$.

Este segundo método era mucho más rentable para el beneficiario del diezmo que el primero. Con sólo dos o tres personas, o incluso una, se podía recoger el diezmo de las eras. Se evitaban fraudes y el diezmo llegaba integramente a la cilla, pues no se sacaban partes de él para el pago del trabajo de llevar los frutos. Además las costas que todo esto ocasionaba, se hacían en dinero, que se entregaba a los perceptores del diezmo prorrata de lo que recogían.

\section{LAS TAMIZAS}

La cantidad de grano y vino que cada labrador entregaba en la cilla era anotada junto a su nombre en la tazmía del año. Por medio de las tazmías se podía conocer quiénes habían cumplido con el diezmo y con cuánto lo habían hecho. Así los encargados del hórreo tenían constancia de los frutos y la cantidad de ellos, que estaban depositados en la cilla. Todo el diezmo que no se llevase al hórreo para el tiempo de la partición, que, en teoría, era la fecha límite para entregarlo, debía anotarse posteriormente y ser entregado como manifestación. También se consideraba diezmo de manifestaciones, aquél cuya cantidad se conocía pero no había sido entregado.

En principio, la suma de todo lo entregado por cada uno de los individuos, debía corresponderse con el total de lo que estaba almacenado en los hórreos, es decir, que lo anotado en la recolección coincidiese con lo repartido y que, por tanto, en ambos casos, fuese la décima parte de la cosecha. Pero esto no era así, como fue observado por los mismos interesados:

«Que el mayordomo no sea obligado a dar cuenta conforme a la tazmía, sino según lo que hubiere en el hórreo, jurando que no ha dado, ni sacado, ni consentido sacar cosa algunas ${ }^{37}$.

Las razones de tal circunstancia son de diversa índole. Desde la fecha de recolección hasta la de reparto, el grano o vino, evidentemente, menguaba en su peso y calidad. Del grano se podían apartar algunas fanegas por ser de muy baja calidad, estar mal aventados o sufrir alguna enfermedad. El vino, entregado en uva, por su proceso de obtención, era impredecible aventurarse en cuanto a la cantidad resultante. Otro ejemplo, en las tazmías se podían detallar partidas de diezmos que no tenían porqué ser llevados al acervo común.

Las tazmías eran confeccionadas por los mayordomos asignados para tal fin, que generalmente, estaban asistidos por el cura de la parroquia o un beneficiado de la

36. A.H.D.Lo. c. 19, 1698. Para poco debió servir tales sentencias porque unos años después, el Cabildo aún se seguía quejando de que varios vecinos llevasen a deshora sus diezmos y algunos con un mes de retraso (1703).

37. C.S., 1602 , f. 84. 
misma. Estos debían elaborar un padrón de todos los parroquianos de la iglesia tanto si diezmaban como no.

En este padrón se anotaba, en época de recolección, qué productos diezmaba cada particular y a cuánto ascendía lo entregado. Se indicaba cada cantidad en letra y la suma al margen. Si algún parroquiano no diezmaba, por no tener de qué, se debía especificar en su lugar "no diezma". En caso de que la cosecha fuese mínima, se debía hacer diezmo prorrata de ella. Cuando no se entregaba el diezmo en el tiempo fijado para ello, se anotaba tal circunstancia y a cuánto ascendía lo devengado. El padrón debía especificar si alguno cogía pan o vino de heredades no diezmeras, indicando la causa de tal exención y a cuanto hubiese ascendido el diezmo; si algún parroquiano llevaba heredades que diezmaban y otras que no, se declararía porqué estaban exentas, cuánto cogió en todas las heredades y cuánto es lo que estaba obligado a diezmar. Se debía especificar si la heredad se encontraba en el término en el que el diezmante era parroquiano o no; si la finca era suya o la tenía a renta, diciendo quien era el propietario y, si era suya, que declarase si era por ser concejil o suya propia. Si la tierra estaba en otro término también se debía decir si era suya o la tenía en renta y de quién la tenía a renta y lo que cogía en ella.

Quince días después — siempre hablando en un sentido teórico- de cogidos los frutos, las personas encargadas de la tazmía y padrón debían leerlo y corregirlo yendo por las casas de los diezmeros para ratificar lo escrito o subsanar cualquier malentendido. Una vez hechas las correcciones pertinentes se debía firmar la tazmía y jurar la veracidad del padrón. En ningún caso, se debía proceder al reparto sin tener hecha, y correctamente, la tazmía ${ }^{38}$.

La confección de tazmías no fue obligatoria hasta el Concilio de Trento por lo que hasta entonces en cada lugar se siguieron diferentes métodos para conocer a los diezmantes y su diezmo ${ }^{39}$. Desgraciadamente para nosotros tal obligatoriedad tardó en cumplirse. Específicamente, en La Rioja se hizo preceptivo a partir de la Sinodal del Obispo Manso de Zúñiga en 1602, fecha a partir de la que se siguió la norma en todas las parroquias. Aún así en algunos lugares no se llevó a cabo con excesiva diligencia como lo demuestran algunas Visitas del Obispo a los archivos parroquiales ${ }^{40}$.

En Santiago el Real de Logroño, cuando se hacían las tazmías, también se especificaba en ellas qué día se echó la primera carga de uva y cuándo se acabó de partir el mosto, las cántaras que había en los diferentes lagos diezmeros de su propiedad. Se detallaba con exactitud lo entregado por cada labrador, si eran diezmos para el cabildo, la fábrica, de anexos, del Cabildo General, de manifestaciones, de cuen-

38. C.S., 1602 , fs. $83-84$.

39. En 1595 en la localidad de Medrano se decía que «las tazmías no se acostumbran a hacer y sólo se hacen unos memoriales», el mismo año, D. Diego de Viana e Ibran, beneficiado en la Imperial de Palacio de Logroño comunica a Calahorra «que en la dicha Iglesia de Santa Maria de Palacio de la dicha ciudad a donde este testigo a sido y es beneficiado, no ha habido ni ay ni se han hecho tazmías en ningún año de los frutos decimales en la dicha iglesia». A.C.C. legs. 2.194/10 y 2.194/8 respectivamente.

40. Se puede ver en A.P.Red. Cuentas de la hacienda de lo Mayor (1635-1689). Y, A.P.Pal. c. 80, f. 14, apdo. 122. 
tas o de cualquier otro concepto. En otros lugares, como Casalarreina o la Redonda desde mediados del XVII, la exactitud, rigor y claridad era una constante, anotando hasta la más leve incidencia. En otros lugares, o se perdieron o no se hicieron, como en Navarrete o Fuenmayor, donde tan sólo se anotaba el diezmo total obtenido a la hora del reparto o en las cuentas de entradas de rentas de los cabildos.

\section{EXENCIONES E INFRACCIONES EN EL DIEZMO}

No siempre se cumplía con el diezmo correctamente. Los labradores entregaban los frutos de peor calidad, menos cantidad de lo debido y, a veces, sacaban de la cosecha una porción para pagar algún arrendamiento, para la simiente o para alguna limosna. En ocasiones se negaban a entregar el diezmo de nuevos frutos (patata, maíz) y en otras, en fin, alegaban estar exentos de contribuir con él.

Estos tipos de infracciones con en el diezmo eran muy frecuentes: en 1760 el Cabildo y Deán de Calahorra y Beneficiados de Agoncillo obligaron a los vecinos de la villa a diezmar la oliva. En 1636 se condenó a D. Lope de León a pagar el diezmo, mitad en Alberite y mitad en donde era parroquiano por tener allí los corderos. En 1763 se multó a un vecino de Muro y Entrambasaguas con 66 rs. y 66 mrs. por no diezmar correctamente. La Mesa Catedralicia de Calahorra obligó en 1666 a Felipe Cabezón, vecino de Alberite, a pagar el diezmo de la escandia, etc. ${ }^{41}$.

Pero si este tipo de faltas eran comunes en todos los lugares y en todos los tiempos, más importante es, para nosotros, tener constancia de que existían otras tantas irregularidades en cuanto a las tierras que debían diezmar.

Heredades que no diezman.

En principio, todas las tierras estaban sujetas a contribuir con su diezmo. La realidad muestra que este precepto no se cumplía. Existían muchas heredades que, por una u otra razón, dejaban de hacerlo en detrimento de sus perceptores o si lo hacían no entraban en hórreo común.

En La Rioja hasta 1539, por sentencia del obispo D. Alonso de Castilla, los Clérigos de Orden, en especial los patrimoniales, no diezmaban de los bienes recibidos como patrimonio para su ordenación. Tampoco lo hacían de lo que compraban o arrendaban, salvo donde existía costumbre inmemorial en contra ${ }^{42}$. También se ha comprobado que las cédulas de los beneficiados de los cabildos, los anejos y muchas de las heredades de las instituciones religiosas dejaban de contribuir con el diezmo.

41. A.C.C. Lb. 232, f. 124; A.P.Red. leg. 1.912 (5-XII-1636); A.C.C. Lb. Mesa Capitular, 1763; A.C.C. Lb. 265, f. 18

42. Sentencia de D. Alonso de Castilla, 1539, recogida por la C.S., 1602, f. 82. 
Las heredades de los conventos y monasterios.

A través de los numerosos pleitos que existen sobre los diezmos y su percepción, en especial los protagonizados por las instituciones eclesiásticas, se puede constatar la proliferación de irregularidades en cuanto a las tierras que debían diezmar y en cuanto a los productos que quedaban sin contribuir.

En el pleito que se desarrolló en Logroño en 1739 entre los Cabildos Eclesiásticos Seculares de Logroño y todas las Comunidades Regulares que poseían alguna heredad en dicha ciudad, se precisa que los establecimientos religiosos, en muchos casos, no incluían entre las tierras que debían diezmar sus propias heredades y las que cultivaban directamente, que las declaraban exentas de diezmos. De las heredades que daban en arriendo, sobre todo los conventos, aparecían ellos como cobradores del diezmo o incluían éste se incluía en el pago de la renta. Y, por último, de las tierras que vendían, trocaban o donaban, se hacían ellos cargo del diezmo o excusaban a los nuevos propietarios de su pago ${ }^{43}$.

Estas prácticas, contrariamente a lo que se suele pensar, estaban muy extendidas y eran norma común desde siempre aunque, eso sí, fueron más manifiestas durante los siglos XVII y XVIII. Prácticas que, por otro lado, no eran nada ajenas a las autoridades eclesiásticas.

Las ventajas para quienes llevaban a cabo o se beneficiaban de tales exenciones eran evidentes. Transcribo a continuación un sentencia del Obispo de Calahorra y La Calzada D. Pedro de Lepe recogida en la Constitución Sinodal de 1698 que, aunque extensa, precisa con una clarividente certeza todo lo dicho y se adelanta con creces a los pensamientos ilustrados de fines del XVIII sobre el diezmo y los efectos que su mal uso ocasionaba en la propiedad de la tierra:

«Y porque hallamos que en estos novísimos tiempos muchas Iglesias juntando con anhelo y estudio muy crecidas cantidades de moneda, procedidas de varias dotaciones, Aniversarios y obras pías que están a su cargo en cuanto a la obligación del cumplimiento; las han empleado, y emplean en comprar heredades de pan llevar, viñas y huertas; las cuales compran muchas veces por precio tan crecido que excede de lo justo. Y si en las almonedas y subastación se las compiten, suelen subir a tanto que doblan el precio de su valor, sin que ningún secular o persona particular se las pueda competir por el conocido exceso de dinero en que las ponen. En lo cual nunca van a perder, porque comprando la heredad se arrogan juntamente el Diezmo de ella, en que tiene mucha utilidad, así por calidad, como por la seguridad de la renta y tenues gastos en su cobranza. Todo lo cual intentan, consiguen y defienden con privilegios mal entendidos y siniestramente interpretados y con costumbres, que verdaderamente son corruptelas; de lo cual se siguen a la República, en lo Eclesiástico y Secular, gravísimos daños, que por muy perniciosos, para que se conozcan y remedien, los debemos expresar. En lo Eclesiástico, el crecimiento de la codicia, el quedar sin dote algunas Iglesias por enriquecer a otras en lo cual no pueden poner remedio... porque con los gastos de los pleitos se empobrecen mas. En lo Secular padece conocido detrimento el común de las Repúblicas, por 
cuanto por este camino se hacen incapaces los Seculares de poder comprar alguno de los muchos fundos y heredades que frecuentemente se suelen vender y públicamente almonedear, y la causa es la insinuada pues ningún Secular puede igualar el precio a que se levanta la heredad, cuando se vende, comprando quien intenta adquirir el Diezmo de los frutos, con el dominio y propiedad de ella. De lo cual se sigue el incomparable daño de no tener los seculares tierras propias que cultivar, valiéndose para ello de tierras tomadas a renta, de cuya cultura sacan ninguna utilidad. Y de aquí, como fuente y principio nace el acabarse o dismi nuirse notablemente las labores de cada lugar, siendo por este camino intolerables las contribuciones pues recaen sobre las personas y no sobre las propiedades, que vendidas en precios regulares quedan igualmente o por la mayor parte entre los Seculares, que las podían comprar.... ${ }^{44}$.

En muchos casos las exenciones de diezmos se hacían por concordato entre las partes implicadas. Esto se hizo frecuentemente entre las instituciones religiosas y, especialmente, entre los conventos (diezmantes) y los cabildos de las parroquias (perceptores), máxime cuando se buscaba el asentamiento de los primeros en algunas villas determinadas.

Los beneficiados de Logroño permitieron ciertas exenciones (de productos y heredades) en los diezmos de los conventos que se asentaron en la ciudad como gracia de dotación, concediéndoselas a las ordenes en su nacimiento como a legos de la infancia y proporcionando alimento en su ternura ${ }^{45}$.

El Monasterio de Santa María La Real de Nájera esgrimió en 1739 que se hallaba en posesión de percibir y llevar para si la mitad de los Diezmos de todas las Heredades que tenía propias en el territorio y campanil de las parroquias de Logroño como ya figuraba en una Concordia de 1382 entre el Monasterio y el Cabildo General de Logroño ${ }^{46}$. El Monasterio de San Millán de la Cogolla no entregaba los diezmos de sus heredades sitas en Azofra, Matute, Cihuri..., el Monasterio de Cañas en las de Hormilleja, el de San Prudencio en los de Tudelilla, Logroño, etc.

El Cabildo de Casalarreina inició pleito en 1647 sobre si las dominicas del Monasterio de Nuestra Señora de la Piedad y las comunidades de religiosos de San Bernardo de Herrera y San Millán de la Cogolla debían pagar el diezmo, que hasta entonces no lo habían entregado de sus propiedades sitas en el campanil de la villa. En el caso de la Piedad, sobre si también debía contribuir por las que tenían en los lugares circunvecinos ${ }^{47}$. Los cabildos de Briñas y Haro consiguieron en 1691 que el Convento de Santo Domingo, orden de predicadores, de la ciudad de Vitoria diezmasen con integridad y fidelidad en las tierras y fincas que poseían en sus territorios ${ }^{48}$.

44.-C.S., 1700, pp. 479-481.

45. A.P.Pal. Libros 39 y 40, sin foliar. Pleito con las Comunidades Regulares de Logroño, 1771.

46. A.P.Pal. Impreso, c. 80, f. 14; apdo. 14.

47. A.H.D.Lo. c. 20. Por supuesto el Cabildo ganó el pleito y se obligó a los monasterios a diezmar 1/10 de las tierras que tenían en Casalarreina y en el caso de las dominicas a entregar también 1/20 de las heredades que tenían en los lugares circunvecinos a la villa "y no trasuman".

48. A.C.C. Lb. 232, f. 217. 
Con la Sentencia Arbitraria dada en 18 de febrero de 1546 por Alvaro de Cabredo y Francisco de San Pedro, como representantes del Cabildo General Eclesiástico de Logroño, se pretendió solventar las diferencias en la percepción de diezmos de las heredades del convento de la Merced de dicha ciudad "y de que manera se habían de labrar y llevar". Se especificaba claramente, primero, que todo el diezmo que los religiosos habían gozado de cuarenta años a esta parte fueran suyos. Segundo, "que todas las [fincas] que dicho Monasterio tuviese, y labrase por si, o sus Criados, o Jornaleros, a sus propias expensas, cogiendo, y llevando el Pan a su Casa, y el Vino a sus Cuevas, propias, o alquiladas, el diezmo de las tales Heredades fuese suyo" no pudiendo llevarse tales diezmos fuera de Logroño aunque las diesen a renta o censo. $\mathrm{Y}$, tercero, que la décima de las tierras que adquiriesen a partir de 1546 y no labrasen por si mismos, se diese a la iglesia donde fuese parroquiano el vecino que la tuviese a renta o censo ${ }^{49}$.

A esta sentencia se remitieron los Mercedarios Descalzos de Logroño en 1740 para fundamentar su derecho de no diezmar desde tiempo inmemorial. Añadieron que "tal decisión había sido comunmente aceptada" por las instituciones religiosas de la ciudad. Los cabildos alegaron que el laudo, que erigía como juez, en los posibles pleitos, al Arcediano de Calahorra, no obtuvo Aprobación Real ni Pontifical, ni se previno a todas las partes interesadas, entre ellas, al Real Patronato.

Con esta concordia sólo se pretendió afirmar las sentencias anteriores porque, como recordó el convento de la Merced, por Bula de Gregorio XI (1370-1378), dada en 1373 a favor de la Religión de la Merced, se le consintió "exención de Diezmos de sus frutos, rentas, y emolumentos, aunque estén concedidos por la Silla Apostólica a los Reyes, Principes, o a otros cualquier, mediante que sacado lo preciso para su manutención, y vestido, lo demás empleaba en redimir Cautivos"50.

El espíritu de tales resoluciones parecen ser el motor de las Sentencias del Ordinario de Calahorra falladas en 1605,1675 y su ratificaciones de 1715 y de 1718, sobre las condenas a perpetuo silencio contra Santa María de Palacio y el Cabildo General de Logroño sobre la pertenencia que tenía el Convento de la Merced sobre los diezmos de sus heredades ${ }^{51}$.

Tomando como modelo la citada concordia de 1546 con los mercedarios, se firmó otra el 27 de marzo del mismo año entre la Universidad de Logroño y el Convento de Valbuena, extramuros de la ciudad, teniendo como árbitros y testigos a los mismos, a la par que las mismas críticas por parte de los seculares en el pleito que iniciaron en $1739^{52}$.

En esta segunda concordia se tuvieron muy presentes "los bienes que en aquel tiempo poseían [los dominicos de Valbuena], y eran ocho fanegas de sembradura,

49. A.P.Pal. Impreso, c. 80, f. 14; apdos. 72 a 78. Alvaro de Cabredo era Maestre-Escuela de la Iglesia Catedral de Santo Domingo de la Calzada y Francisco de San Pedro, Arcediano de dicha Iglesia.

50. A.P.Pal. Impreso, c. 80, f. 14; apdo. 147.

51. A.P.Pal. Impreso, c. 80, f. 14; apdos. 142 a 146.

52. A.P.Pal. Libros 39 y 40. 
plantadas de olivas, 136 obradas, plantadas de viña, 23 fanegas de tierra, y diversas huertas, y casas, sitas en ellos, cuya cabida no se expresa". Bienes que poseía desde hacía más de cuarenta años, a excepción de 9 fn de tierra, 3,5 obradas de viña y algunas de las huertas ${ }^{53}$. Otras concordias fueron del mismo estilo, como la del 12 de abril de 1547 entre el convento de Madre de Dios y los Cabildos de Logroño ${ }^{54}$.

La Compañía de Jesús asentada en Logroño también expuso, en diversos pleitos, documentos que la hacían poseedora de diferentes prerrogativas sobre el contribuir en materia de diezmos. Y ya en 1629 la Congregación de las Santas Iglesias Metropolitanas y Catedrales de Castilla y León mandaron averiguar la hacienda que tenían los padres de la Compañía en Logroño y en qué consistían, para saber los diezmos que dejaban de pagar ${ }^{55}$. Según mostraron en el pleito iniciado en 1739 con los cabildos logroñeses, la orden jesuítica estaba exenta de los diezmos de ciertas heredades sitas en el término campanil de Lardero, siendo el último documento presentado, el concedido por el obispo D. José Espejo y Cisneros (1717-1747) en el año de 1737 que no hacía más que ratificar los derechos concedidos con anterioridad ${ }^{56}$.

Por Concordia entre el Rector del Colegio Jesuita de Logroño D. Luis Díez de Moretín, y los Canónigos de la Redonda, D. Antonio López Barrionuevo y D. Pedro de Lavid, en fecha de 29 de abril de 1651, se determinaba que la Compañía pagase los diezmos en cada un año de

«los frutos de pan, vino y aceite y los demás que se cogieren en el pago de Atayo... de las heredades que labrasen a sus expensas de cuarenta una y de lo arrendable y labrado por colonos de veinte una sin que se pueda pretender limitación ni aumento por ninguna de estas partes respective ahora ni en ningún tiempo»

con la única condición de que si, por cualquier causa, la Redonda perdía sus derechos sobre los diezmos del término de Atayo quedase "el dicho Colegio libre y fuera de la obligación de esta escritura", pudiéndose entonces establecer cualquier otro compromiso con los nuevos usufructuarios ${ }^{57}$.

La concordia anterior pretendía acabar con los reiterados problemas que entre ambas partes existían, junto con los onerosos gastos en pleitos que conllevaba. Por similares motivos, ocho años antes, en 1643, la misma Colegial, a título personal, pretendió recortar lo que consideraba abusos en la percepción de los diezmos por parte del Convento de Valbuena: la Redonda acusaba al convento de entregar en arriendo muchas tierras libres de pagar diezmos, y quedarse con los de las que culti-

53. A.P.Pal. Impreso, c. 80, f. 14; apdos. 140 y 141. En todo caso, es lógico pensar que en la concordia con la Merced también se contabilizasen sus propiedades adquiridas desde, al menos, hacía más de cuarenta años.

54. A.P.Sant. lg. 2, f. 53. Realizada por la abadesa, María Enciso, y monjas de dicho convento y el Cabildo General. Y A.P.Pal. Impreso, c. 80, f. 14; apdo. 149.

55. A.P.Red. nos 1709 y 1718 .

56. A.P.Pal. Impreso, c. 80, f. 14; apdos. 150 a 152.

57. A.P.Red. $n^{\circ} 2.141$. 
vaban directamente ${ }^{58}$, aunque, como dijo un parroquiano de la Colegial esto a sido y es tan publico y notorio en dicha ciudad [de Logroño] que tiene por cierto que si no tuvieran algún derecho para arrendarlas [las fincas] libres de diezmos a los colonos y arrendatarios no lo hubieren consentido ${ }^{59}$.

El 14 de diciembre de 1656 se envió al abad y monjes del Monasterio de San Prudencio, de la orden de San Bernardo, una carta advirtiéndoles de excomunión sino entregaban los diezmos y primicias de Palazuelos ${ }^{60}$. La intransigencia del monasterio a no diezmar de las heredades que había adquirido en dicho término, junto a sus intenciones de redondear sus compras con otras nuevas a las que aplicaría similares criterios en asuntos del dezmar ${ }^{61}$ llevó a la Colegial de la Redonda y Albelda a mostrarse tan rotunda.

Aunque la excomunión no llegó a llevarse a cabo, sí se consiguió, que al año siguiente, se firmase entre ambas partes una Concordia que, no fue lo suficientemente provechosa para la Redonda. En ella se establecía que la parroquia de Albelda (unida a la Redonda) tenía el "derecho privativo" de llevarse todos los diezmos y primicias de Palazuelos, así de pan y de vino como de otros cualesquiere géneros de frutos en los que toca a sus Parroquianos [de Albelda] de diez uno y en lo que toca a los vecinos de Clavijo o otras partes que no trasumen, de veinte uno. Se excluía de tales preceptos las doce fanegas de tierra que poseía el monasterio en dicho término, consideradas como propiedades iniciales o fundacionales (que eran sólo de sembradura de secano), las cuales se le daban por libre de la obligación de diezmar y primiciar siempre que las labrasen y cultivaren por sus criados como granjería del convento con que las arrendaren paguen los colonos. Además de establecer que las fincas, que para fecha de 8 de marzo de 1650 en adelante se comprasen o permutasen, debían primiciar de treinta una y diezmar de diez una; precisando que si algún celemín, de las doce fanegas arriba indicadas, cambiase de dueño, el nuevo propietario debía diezmar y primiciar ${ }^{62}$. Estos problemas no terminaron aquí.

Al año siguiente, 1658, el Deán y Cabildo de la Redonda no tuvieron más remedio que aceptar el derecho del abad y monjes de San Prudencio de no pagar los "diezmos de los corderos, cabritos, queso y lana" que produjesen "en los términos de Clavijo, Palazuelos y Albelda para el sustento de los monjes de dicho convento, su familia, curados, huéspedes y ministeriales"63.

Idénticos problemas tenía el referido Monasterio con el Cabildo de Santa María de Villamediana. Por sentencia de 1705 estaban condenados a diezmar de todas sus heredades sitas en el custerio de la villa ${ }^{64}$.

58. A.P.Red. nos $1.892,1.893$ y 2.023 .

59. A.P.Red. $n^{\circ} 2.023$.

60. A.P.Red. $\mathrm{n}^{\circ} 2.279$.

61. A.P.Red. nos 2.108 y 2.113 .

62. A.P.Red. $n^{\circ} 2.285$.

63. A.P.Red. $n^{\circ} 2.308$.

64. A.C.C. Lb. 265. f. 15. 
La Compañía de Jesús con casa en Logroño había adquirido en Lardero para 1588 "muchas heredades hasta en cantidad de cinco o seis mil ducados de piezas, viñas y olivares" y tenían casa y granja en el mismo término. Los beneficiados de Lardero se quejaban de que se llevaban todos los diezmos de lo que cogen en las dichas heredades que compraron y por ello han quitado mucha parte de los diezmos del cabildo $y$ beneficiados ${ }^{65}$.

Todas las anteriores resoluciones y concordias que limitaban o, al menos, singularizaban la cuantía o el medio de entrega del diezmo de las heredades propias de los conventos, monasterios y otras instituciones religiosas no fueron particularidades de La Rioja. En otros lugares de España ocurría otro tanto. El Cabildo y Beneficiados de las Iglesias Unidas de Miranda de Ebro obligaron en 1732 al Convento de San Miguel del Monte a diezmar de todas las heredades que tenía en los campaniles de las primeras $^{66}$.

A. Alberto Martín comprobó que en la Diócesis de Palencia ciertas cofradías, iglesias, órdenes religiosas y algunos eclesiásticos no acostumbraban a pagar diezmo de sus tierras a no ser que las hubiesen cedido para su cultivo a otras personas ${ }^{67}$. En Zaragoza, Atiénza López, ha encontrado compromisos similares para comienzos del siglo XVIII entre el Arzobispo de Zaragoza y algunas comunidades regulares en lo referente al diezmo del ganado ${ }^{68}$.

\section{Los anexos}

Era frecuente encontrar heredades que contribuían con el diezmo, pero que tal diezmo no era aprovechado por todos sus legítimos perceptores sino tan sólo por el propietario de esas tierras "so color de anexos". De tal manera, se omitía el preceptivo paso de manifestar el diezmo en hórreo común y escapar del control obispal.

Los anexos eran las heredades aniversariadas, sobre las que existía alguna capellanía, memoria, fundación, eran propiedad de cofradías, componían las cédulas de los beneficiados de mayor ración de los cabildos o formaban parte del patrimonio de eclesiásticos, de arcedianos, de alguna encomienda, fábrica, ermita o cualquier otra institución eclesiástica.

Su existencia es patente en todas las localidades de La Rioja. En todas ellas, siempre se tendió a ocultar su cuantía. La mejor manera de hacerlo era no llevando los diezmos de tales heredades al acervo común de la localidad para escapar así del control que sobre ellas podía realizar el Obispo o cualquier otro beneficiado de los diezmos. La razón última era que sus usufructuarios no tenían documentos con que pro-

65. A.C.C. leg. 2.194/17. Las heredades las tenían sitas entre el término de Lardero junto al de Logroño donde "llaman de Vedadillo".

66. A.P.Sant. leg. 5, f. 5.

67. MARCOS MARTÍN, A. 1983, p. 106.

68. ATIENZA LÓPEZ, A. 1988, pp. 89 y ss. y 127 y ss. 
bar su derecho, sino basándose en la costumbre y, ni siquiera sabían si su propiedad procedía de privilegio o concesión ${ }^{69}$.

Por esto las Iglesias Catedrales, léase Santo Domingo o Calahorra, que en casi todos los lugares eran beneficiados con una proporción de diezmo, lo primero que pretendieron fue conocer la cuantía de tales "anexos" para ir poco a poco limitándolos a cánones fijos o, en su defecto, a un número de heredades especificas. Fue sumamente difícil de llevar a cabo tal pretensión, puesto que al progresivo aumento de tales tierras se unían las particularidades y concordias existentes en cada una de las villas al respecto ${ }^{70}$.

En la Constitución Sinodal de D. Pedro Manso de Zúñiga de 1602 se obligó, de una manera pública y general, a entregar al acervo común todos los diezmos de anejos. La sentencia se fue cumpliendo paulatinamente donde todavía no se hacía. No por ello dejaron de percibir tales beneficios las mismas personas e instituciones que antes ${ }^{71}$.

Aunque ya en 1552, por concordia entre la Catedral de Calahorra y el Cabildo de Beneficiados de Laguardia, se estableció que los diezmos de anejos entrasen a hórreo común, fue a partir de la segunda mitad del siglo XVII cuando se hizo más hincapié en el tema. En Ausejo ya para 1664 lo hacían y los beneficiados "sacaban" de los diezmos sus anejos antes del reparto; en Navarrete se acordó en 1691; en San Vicente de la Sonsierra en 1700 , etc. $^{72}$.

Las heredades sujetas a aniversarios que existían en Quel y de las que se llevaban enteramente los diezmos sus Beneficiados, tenían la cláusula especial de que si se arrendaban, los arrendatarios quedaban libres de entregar los diezmos ${ }^{73}$.

En Briñas, después de varios pleitos, se estableció concordia en 1683 entre el Obispo y el Cabildo de la Villa por la que todos los frutos decimales se debían llevar al hórreo común, entregando la cuarta parte para la Mesa Capitular y el resto para el Cabildo de Briñas. De la cuarta parte que correspondía al Obispo se entregarían, en concepto de "anexos", 60 cántaras, de vino para el Arcediano de Nájera. Si el arcediano no estuviera conforme con esa cuota fija y existiere pleito, pagarían las costas los Beneficiados de Briñas así como cualquier aumento de las 60 cántaras. ${ }^{74}$.

En Casalarreina el Deán y Cabildo de Santo Domingo de la Calzada, como perceptor del "cuarto" de Casalarreina, interpusieron pleito contra el Cabildo de la Villa en relación a los "anexos" y la parte que le correspondía al Condestable de Castilla de los diezmos de la Villa. Como el pleito era largo y costoso y la cantidad sobre la

69. A.P.Sant. leg. 2, f. 49 (segunda mitad del XVIII).

70. A.P.Sant. leg. 2, f. 49 (segunda mitad del XVIII).

71. C.S., 1602 , f. 84.

72. A.C.C. Lb. 265: Laguardia, 1552, fs. 40 y ss. Ausejo, 1664, fs. 3 y ss. Navarrete, 1691, fs. 36 y ss. San Vicente de la S., 1700, f. 44. 1664.

73. A.C.C. Lb. 265, f. 10 y ss. Según concordia entre la Catedral de Calahorra y Quel en fecha 17-VII-

74. A.C.C. Lb. 265 , Briñas, fs. 52 y ss. 
que se fundaba era poco considerable, determinaron que, a partir de 1648, fuese el Cabildo de Casalarreina quien se llevase los diezmos del Condestable a cambio de $5.000 \mathrm{mrs}$. Dinero que se debían entregar en Calahorra y se sacasen como anejos, tan sólo 200 cantaras de vino, ahora se coja mucho o se coja poco sin que de estas tenga parte la dicha Iglesia Catedral. En la década siguiente los anejos estaban compuestos, además de por vino, por 4 fns. de trigo y otras 4 de cebada ${ }^{75}$.

Percibían los anejos, en general, las instituciones religiosas pero, en particular, los cabildos de beneficiados de las parroquias por tener adscritas tales heredades como propiedades vinculadas, sobre las que existía alguna fundación, capellanía, obra pía o, sencillamente, la propiedad era de una cofradía que estuviese asentada en su parroquia.

Los diezmos declarados como anejos que se llevaba el arcediano de Nájera de Navarrete, llegaron a no entrar en el hórreo común. Unido ésto a la poca claridad que existía sobre su cuantía llevó al Cabildo de la villa a pleitear con el Sr. Manzanos, entonces arcediano. Se estableció que los diezmos entrasen en el hórreo, que fuesen una cantidad porcentual - la novena parte de los frutos del tercio de la Mesa Capitular-. El resultado fue que el Obispo se llevaba 8/27 del diezmo ${ }^{76}$. En Bobadilla en 1731 se obligó al arcediano a que diese de los diezmos anejos que 1levaba, la tercera parte al Obispo, es decir, que hasta esa fecha los diezmos de anexos de Bobadilla se escapaban al control de Calahorra ${ }^{77}$.

Los problemas que causaban los anexos para los perceptores de los diezmos, perduraron hasta la desaparición del propio diezmo. En este sentido, qué duda cabe, las más perjudicadas eran las Mesas Catedralicias que veían menguar los montones de granos y las cargas de uva en todas las localidades de su obispado y, como consecuencia, sus rentas procedentes de su participación en el diezmo.

Sobre la cuantía que suponían los anejos sólo tenemos noticias fragmentadas y escasas. Tanto el creciente interés por su control como el hecho innegable del crecimiento de las propiedades rústicas por parte de los eclesiásticos, nos inducen a pensar que su importancia en relación al diezmo total fue en aumento con el transcurso del tiempo ${ }^{78}$.

75. A.H.D.Lo. Casalarreina, c. 19.

76. A.C.C. Lb. 265 , fs. 36 y ss. Sentencia de $4-X I-1691$.

77. A.C.C. Lb. 232 , f. 217.

78. Como ya hemos dicho en Briñas tan sólo suponían 60 cántaras, cantidad desdeñable para la el diezmo de vino de la villa. En Casalarreina suponían no mucho más del $8 \%$ del total del vino entregado y escasamente el 3\% del trigo en el siglo XVII. En Lardero los anejos lo componían, según el subsidio de 1595, 20 fns. de tierra entre «la Encomienda de Buradón que tiene en dichos términos de dicho lugar y las heredades sobre las que estaban cargadas algunos aniversarios y de los patrimonios de los clérigos y ermitas de dicho lugar». En Entrena, según ese mismo subsidio, los diezmos de anejos además de repartirse exclusivamente entre los beneficiados una vez entregadas las 32 fns. de pan mixto al Arcediano de Calahorra y las 2,5 de sólo trigo al Arcipreste, suponían (según la media de 1588-1592) el 46,4\% del trigo, el 37 de la cebada, el 28,4 del centeno, el 25,5 de la avena y el 4,3\% del vino, únicos productos sobre los que existía «anexos» A.C.C. leg. 2.194/17. A.C.C. leg. 2.156. 
Las cédulas de los beneficiados

El otro gran grupo de tierras que quedaban fuera del alcance de la contribución decimal eran las cédulas. Las disfrutaban los beneficiados o censales, como se conocían en La Rioja Baja.

Las cédulas eran el conjunto de bienes, sobre todo tierras, que ciertos beneficiados por su condición, generalmente los de mayor ración (ración entera y media), tenían como bienes propios en usufructo. Dichos bienes pertenecían a la iglesia de la que formaba parte y las rentas que generasen aumentaban el "sueldo" o ración de su cargo.

Las tierras que formaban parte de las cédulas estaban exentas de contribuir con el diezmo al ser consideradas como de dote y manutención de los primitivos beneficiados $^{79}$. Esta es la razón de que únicamente disfrutasen de estas heredades los beneficiados de ración entera, puesto que, se supone que la creación de beneficios $m e-$ dios, cuartos y otros se producían en el momento que había sobrecrescencia de frutos (aunque existe la posibilidad de alguna excepción).

Sobre la extensión de tierra que podían suponer estas cédulas tenemos escasas noticias. Según un documento de 1595 referente al subsidio, las cédulas de los beneficiados de la Redonda de Logroño les rentaban al año 473,5 fns. de trigo y 1.791,5 mrs. ${ }^{80}$. A mediados del siglo XVIII los cinco beneficiados enteros de la iglesia de Santiago de la misma ciudad, disfrutaban de cinco cédulas: la $1^{\text {a }}$ de 15 fanegas de tierra, la $2^{\mathrm{a}}$ de 21,5 , la $3^{\mathrm{a}}$ de 24 , la $4^{\mathrm{a}}$ de 15,5 y la $5^{\mathrm{a}}$ de 15 ; además la segunda cédula tenía 3 obradas de viña. Todos sus poseedores declararon que recibían de ellas tanto sus rentas como los diezmos que generaban ${ }^{81}$. Las sillas de esos mismos beneficiados componían en 1772 unas rentas de 128,5 fns. de trigo y 2.541 maravedís. Concretamente, las del Señor Amescua, D. Domingo Ibarra y D. Nicolás de Adana, percibían el diezmo de trece tierras de secano, olivar y viña de diversos vecinos de la ciudad ${ }^{82}$.

Se ha podido comprobar que los propios beneficiados, e incluso los cabildos, tenían tierras que no contribuían con el diezmo junto con otras que las daban a renta exentas de él ${ }^{83}$. Don Bernabé Blázquez, beneficiado entero en Santiago en 1731 dió en arriendo su beneficio por renta de 400 ducados en cada un año de cinco, a Juan Ramón de Tuyereta, el cual se obligo a la paga de dicha cantidad, y a la de los gastos ordinarios de dicho Beneficio y expresando Don Bernabé a servir y cumplir con todas las cargas de el y a los de pleitos en defensa de los frutos decimales y rentas de dicho Beneficio ${ }^{84}$. En Calahorra existían tierras propias de los Cabildos, los "censales", que en algunos casos no diezmaban y en otros únicamente la mitad ${ }^{85}$.

79. A.P.Sant. Lb. 112 (1776) y leg. 2, f. 32.

80. A.C.C. leg. 2.161.

81. A.P.Pal. c. 80 , f. 14, apdo. 118.

82. A.P.Sant. leg. 2 , f. 52 .

83. A.P.Sant. leg. 2, f. 32. A.P.Pal. c. 80, f. 14, apdos. 114 y ss.

84. A.P.Pal. c. 80 , f. 14 , apdo. 158.

85. A.H.P.Lo. Catastro, c. 144, vol. 167. En Murillo de Calahorra no diezmaban ni primiciaban, A.H.P.Lo. Catastro, vol. 451. 
Debido a las divergencias que creaban estos privilegios entre los perceptores de los diezmos, en la segunda mitad del siglo XVIII, se procedió a suprimirlas. A partir de 1776, y tras diversas peticiones y sentencias obispales, se comenzaron a diezmar de todas estas cédulas y de aquellas tierras que pertenecían a los cabildos y fábricas, al menos, en la ciudad de Logroño ${ }^{86}$.

\section{Infracciones}

Tanto los pleitos que hemos encontrado como las Sinodales, insistían más en la calidad de los productos diezmados que en la cantidad. Era muy común el entre gar como diezmo lo peor de los productos recogidos en la cosecha, levantando de las eras el grano y reservando la última parva para pagar el diezmo ${ }^{87}$. Era habitual entre gar mezclas de productos: el trigo con el centeno, la cebada con la avena... sin que siempre existiese una proporción equivalente entre ellos lo que posteriormente iba en detrimento de los interesados en el diezmo, pues se veían obligados a venderlos a bajos precios ${ }^{88}$.

El diezmero no debía recoger los frutos por la noche "en atención a los inconvenientes que se siguen a todos midiendo de noche" y siempre procuraría tomar correctamente la décima a todos los parroquianos sin distinción de su categoría social. Se trataba de evitar que grandes propietarios, regidores, nobles, etc. no diezmasen en las eras o, sencillamente entregasen menos cantidad que la que les correspondía por la presión que sobre el preceptor pudiesen ejercer.

En el ganado era donde más problemas existían para recaudar la décima parte. El propietario se solía negar a diezmar, aduciendo que decían ya lo había hecho en Extremadura o Andalucía cuando los llevaron a invernar, o durante el camino, o habían pacido en Dehesas privilegiadas de diezmo ${ }^{89}$.

En el grano era frecuente hacer todo tipo de sacas antes de diezmar. Para la simiente; para pagar las rentas; para dar limosnas; para costas de pleitos; para comidas y emolumentos, etc..$^{90}$.

Problemas de otra índole eran los que acaecían cuando se comenzaban a cultivar nuevas semillas. Los vecinos esgrimían siempre que como no había costumbre de hacerlo estaban exentos de contribuir, aunque las Sinodales eran rotundas:

«Así mismo, mandamos que si a alguna Provincia, o lugar de el Obispado, fuere traída alguna semilla no acostumbrada a sembrarse hasta aquí en ella y se introdujere el sembrarla, se pague Diezmo de ella, en la forma que de todas, sin que se pueda defender con la costumbre no haber paga-

86. A.P.Sant. Lb. 112.

87. C.S., 1700 , pp. 470 y 472.

88. Ver C.S., 1700, pp. 483-484.

89. Sinodal de D. Pedro de Lepe, Logr. 1698, pp. 474-475.

90. Por no estenderme en los numerosos ejemplos daré como única referencia la Sinodal de D. Pedro de Lepe, Logr. 1698: 471-490. 
do de ella; porque no puede alegarse costumbre de no pagar Diezmo de aquello, que no se ha diezmado, por no tener existencia»"1.

Algo similar ocurría con las tierras que se roturaban, las tierras novales. Aunque por la Concordia de 24-IV-1664 se había establecido que en Alberite se pagarían los diezmos "de las tierras concejiles roturadas" que pusieron en cultivo, al año siguiente se inició un nuevo pleito sobre el mismo asunto. Los vecinos de Alberite no diezmaban de los frutos "que habían cogido en cantidad de heredades que nuevamente habían roturado, labrado y sembrado en diferentes términos concejiles [en los Prados del Sotillo y el Eral] de dicha villa". La villa, además de esgrimir que, como eran nuevas tierras, no tenían porqué diezmar, también alegó que su negativa estaba vinculada al incumplimiento, por parte de los perceptores del diezmo, de las pitanzas y colación que debían disfrutar el alcalde y regimiento como contrapartida a que los vecinos llevasen el diezmo al hórreo. Añadían que los recaudadores no habían cumplido fielmente con los réditos de varios censos que existían contra la villa, como se había acordado.

Entre las partes interesadas (la Justicia, Concejo y vecinos de Alberite por una parte, y la iglesia de Palacio de Logroño, la Mesa Capitular de Calahorra y los Beneficiados de la villa, por la otra) se siguieron diversos pleitos. Al final los vecinos de Alberite tuvieron que ceder en cuanto al diezmo, pero no sin lograr algunas victorias. Por sentencia de 1668 se eximió a la villa de entregar los diezmos que correspondiesen de las tierras novales de años pasados; se fijó la cuantía de la pitanza de la que debía disfrutar la alcaldía y se concordaron los pagos de los réditos ${ }^{92}$.

En otros lugares como en la Parroquial de la Anteiglesia de Berriatua ocurría otro tanto. En 1751 el Cabildo y beneficiados consiguieron que el Conde de Florida, Patrono Presentero de los Beneficios de ella, satisfaciére los diezmos novales que se cogían en su termino campani ${ }^{93}$.

También era frecuente defraudar a los arrendatarios de los diezmos en cuanto a la proporción del diezmo que les correspondía y a la cantidad de los mismos, lo que ocasionaba no pocos problemas a los legítimos poseedores, pues cuando volvían a administralos debían pleitear por lo que era suyo ${ }^{94}$.

\section{Los Beneficiarios DEl Diezmo}

La Iglesia no era la que percibía la totalidad de los diezmos, aunque sí la parte más importante, en un 70\% según E. Canales. Esto suponía la tercera parte de todos sus ingresos y figurar como uno de los más importantes pilares de su economía. Los

91. Sinodal de D. Pedro de Lepe, Logr. 1698: 471.

92. A.C.C. leg. 2.914. Lbs.: 232, fs. 175 y 178; y 265, f. 17 y ss. Los réditos y pagos corresponden al censo de 600 dcs. que D. Jerónimo Ponce de León había puesto contra la villa de Alberite; el censo de D. Andrés Fernández de la Pradilla y por el Yantar.

93. A.P.Sant. leg. 1, f. 4.

94. C.S., 1700: 477-478. 
compartía con el Estado a través de las Tercias Reales (2/9 del diezmo), el Excusado (el importe de la mayor casa dezmera de cada parroquia) y el Noveno Decimal (1/9 del diezmo en 1800), es decir, un $20 \%$ de los diezmos. Además estaban los partícipes laicos, señores titulares de diezmos, quienes venían a controlar alrededor del $10 \%$ del total del diezmo aunque con muy marcadas diferencias regionales (mayor en Cataluña que en otras regiones $)^{95}$.

Dentro de la Iglesia, el diezmo se caracterizaba por estar mal repartido. El clero parroquial, sobre el que recaía la mayor parte de la labor pastoral, tan solo se llev aba la mitad. Los Obispos, conventos, monasterios, capítulos catedralicios y altas dignidades eclesiásticas, más del 20\%, variando del 49,5\% de los diezmos en la Seo de Urgel, al 18,8\% de Tarragona y el 24\% para los curas párrocos en Segovia. El destino de esta parte solía ir a parar a mantener el alto nivel de sus perceptores y la magnificencia del culto en las catedrales, "las atenciones específicamente pastorales y caritativo-asistenciales ocupaban, de ordinario, un lugar secundario entre obispos y canónigos" ${ }^{\prime \prime}$.

Pretendiendo establecer quiénes eran los destinatarios de los diezmos en La Rioja se han tomado del Catastro de Ensenada una muestra de 86 cillas, cerca de la mitad de las existentes. Lo primero que destaca en ellas es que ninguna institución o individuo participaba en el diezmo de todas los hórreos. Segundo, que el porcentaje de participación era totalmente dispar (de llevarse todo a no percibir nada) y, por último, destaca su complejidad.

Unos llevaban diezmo únicamente de determinados productos y no de otros. Lo hacían en una proporción o en otra. Se tomaban antes del reparto o se los debían proporcionar el cabildo una vez abonados los gastos, dado el tercio al Obispo y añadidos los anejos devengados del comunero...

Así por ejemplo, el diezmo del hórreo de la Colegial de Alfaro pertenecía a las siguientes dignidades e instituciones. Lo que diezmaba la Encomienda de San Antonio, a la misma Encomienda. La Dignidad del Chantre y Tesorero llevaba los diezmos enteros de ciertas tierras; la Iglesia Catedral de Tarazona la cuarta parte del vino, lana, cáñamo, lino, legumbres, trigo, cebada y cardón. El Cabildo y Beneficiados de la Colegial, la mitad del centeno y avena y la cuarta parte del trigo, cebada y cardón. El Abad de la propia Colegial 20 cargas de trigo y cebada antes del reparto, la tres cuartas partes del vino, corderos, lana, cáñamo, lino y legumbres y la mitad del centeno y avena. El resto, unas partes sobrantes, el cuarto prebendado, y diversas sacas anteriores al reparto: para el Sobrestante General, el cura coadjutor, el secretario del cabildo, el procurador y para maitines ${ }^{97}$.

Se comprenderá que teniendo varios casos como este, es difícil establecer con precisión quién se beneficiaba de los diezmos. Por ello se ha tomado de los hórreos

95. CANALES, E. 1985: 245-250.

96. CANALES, E. 1985: 247. También se puede ver GARCÍA SANZ, A. 1977: 313-318. Y del mismo, 1975: 143-152.

97. A.H.P.Lo. Catastro, vol. 45. 
únicamente el porcentaje de lo que percibía cada uno del trigo, la cebada, el centeno y la avena (los cereales mayores) a sabiendas de que en algunas villas los menuceles (sobre todo animales, lana e hilaza) eran productos mayoritarios o que el vino seguía el mismo reparto que los granos pero de él se realizaban menos sacas.

De todo ello se ha eliminado el porcentaje de lo que iba destinado a gastos (gastos de recogida, almacenaje hasta el reparto, pagos a mayordomos, medidores, a los diezmantes por llevar el grano a los hórreos, etc.). Aunque en este apartado nos sale un 3,4\% del diezmo, creemos que, en realidad, estaba entre el 5 y $10 \%$, pues en algunas cillas se omiten estos gastos y, debido a que eran rentas fijas el porcentaje variaba según fuese mayor o menor la cosecha.

Lo que no cabe duda es que en La Rioja los principales destinatarios del diezmo eran los Cabildos y Beneficiados de las iglesias (con cerca del 60\% del diezmo y en el 66\% de los hórreos), las Mesas Catedralicias y la Dignidad Episcopal (con un $20 \%)$.

Los Cabildos recibían mayoritariamente el diezmo de sus propias cillas (cerca del $50 \%$ ) por derechos adquiridos (donaciones, concordias, dotaciones fundacionales...), a través de tierras cuyos diezmos percibían particularmente (anejos, cédulas), en casos menos frecuentes, los ganaban por mayordomías y gastos ocasionados por su control. Ahora bien, algunas villas, dispusieran o no de cabildo propio, debían entregar parte de sus diezmos a cabildos establecidos fuera de su custerio (alrededor de un 10\%), bien por donaciones (Alberite al Cabildo de Palacio de Logroño), bien porque pertenecían al dezmatorio de alguna iglesia (Arnedo percibía los diezmos de Arnedillo, El Villar, Tudelilla, etc.) o porque la primitiva iglesia a la que debían diezmar había desaparecido y la tierra había pasado a formar parte de la jurisdicción de una villa y los diezmos a otra (es el caso del término de Palazuelos sito en Clavijo y dezmatorio de la Redonda de Logroño).

Dentro de los Cabildos se ha incluido la parte que llevaba el Cura puesto que, generalmente, era un sexto de una ración entera o incluso un cuarto (Arnedo). En otros casos se le entregaba una porción muy reducida de los diezmos y en cantidad fija (en Corporales 8 fanegas de trigo y otras tantas de cebada). En este último caso se ha podido constatar que, como media, no se llevaba más del $1 \%$ de los diezmos totales ${ }^{98}$.

Los otros grandes destinatarios de los diezmos (que hemos agrupado en una misma sección porque no se establece con claridad quién era el destinatario final) eran las Mesas Catedralicias (sobre todo Santo Domingo y Calahorra aunque tam-

98. Las Sinodales especifican que al rector, que en cada iglesia debe haber y al que está encomendada de manera especial las animas de los clérigos y legos, perciban una proporción mayor en los diezmos por su servicio, estableciendo que será la norma general un sexto más «pues los tales tienen mayor trabajo que sus compañeros»; ahora bien, si dichos curas percibían de otro tipo de rentas, primicias o limosnas, que ya les diferenciaba con sus compañeros en un sexto, llevaban de los diezmos igual que sus compañeros; si hubiese dos curas sería una sexta parte dividida entre dos y si se producía un relevo en el cargo de cura en el año se debía hacer prorrata y se llevaría cada uno según lo que estuvo en su cargo». Sentencia de D. Diego de Zúñiga dada en 1410 y recogida por la C.S., 1602, fs. 59-61. Ver también LLORENTE, J.A. (presbítero), 1789: 27 y ss. 
bién la Metropolitana de Burgos —en Ezcaray- o la Catedral de Tarazona - en Alfaro-) y la Dignidad Episcopal quienes llevaban diezmos de un $60 \%$ de las cillas.

Lo más frecuente era que el Obispo y las Catedrales llevasen la tercera parte de los diezmos, en algunos hórreos no llevaban nada (Alcanadre, Fuenmayor, Alfaro -parroquia de San Miguel—, Logroño — parroquia de San Salvador y San Blas—, Camprovín), en otros era la cuarta parte (Briñas, Cidamón, Leiva, Haro). En menos casos, le correspondía al obispo dos tercios (Alberite) e incluso en algunas cillas se llevaba ínfimas cantidades (Logroño — La Redonda—, Villalobar, Bañares, Villamediana) ${ }^{99}$.

Las fábricas de las iglesias percibían en muchas cillas alguna renta fija procedente del diezmo, en su mayor parte, en concepto de arrendamiento de trojes u hórreos. Lo raro era que se llevasen una cantidad proporcional aunque existen ejemplos de ello: en Castañares de Rioja un cuarto, en Cellórigo un noveno, en Matute otro noveno.

El resto del diezmo, menos de la sexta parte, se lo repartían entre arcedianos, arciprestes, señores jurisdiccionales, Tercias Reales, Monasterios, Conventos y en algunos casos las villas (un tercio en Anguiano y Alesanco).

Los señores jurisdiccionales se beneficiaban (en no más de un 7\%) del diezmo, principalmente, a través de sus derechos sobre algunas villas: en Alcanadre el Conde de Murillo se llevaba la totalidad del diezmo, en Ojacastro el Duque de Frías cerca del $40 \%$ del diezmo de la villa, en Ezcaray y sus aldeas el Duque de Medinaceli la quinta parte, etc. Pero también lo hacían por medio del arrendamiento de las Tercias Reales: en Casalarreina (Condestable de Castilla), Pedroso (Señor de Viloria), Hervías (Conde de Hervías), Foncea (Duque del Infantado), etc. constatando que raramente esas Tercias eran realmente 10 s $2 / 9$ del diezmo. No hemos encontrado ningún caso donde el Rey se beneficiase directamente de ellas.
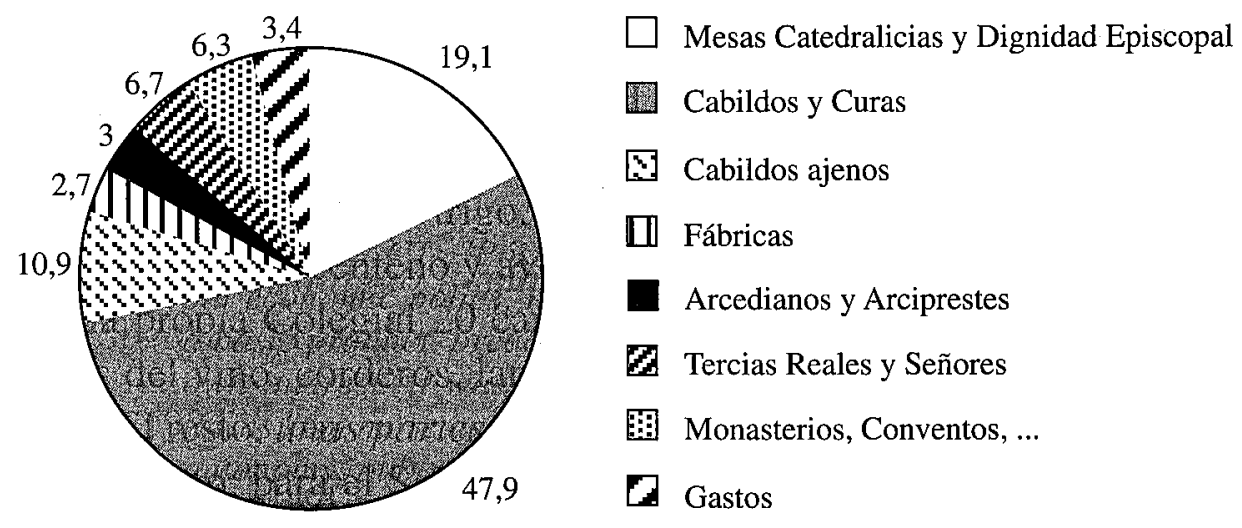

Participación en el diezmo de trigo, cebada, centeno y avena. Porcentajes. Muestra de 86 cillas de La Rioja.

99. El porcentaje de los diezmos que se llevaba la Dignidad Episcopal difería, no sólo entre un lugar y otro, sino que incluso en una misma villa, pues las porciones eran diferentes según los productos; sirva un ejemplo: En Briones le pertenecían la cuarta parte de todos los diezmos «mayores y menores» excepto del vino, del que se llevaba una cántara de cada cinco y media. A.H.P.Lo. Catastro, vol. 155 y ss. En Alberite esos dos tercios del diezmo se repartían entre la Mesa de Aniversarios y la Capilla de Cantores de Calahorra. A.C.C. Lb. 265, f. 17. 
Los monasterios, conventos y ciertos Hospitales eran los que contaban con mayor número de tierras exentas de contribuir con el diezmo, es decir, se trataba de diezmos que no llegaban al acervo común. La proporción que suponían del monto total es incuantificable, aunque sabemos que en algunas villas suponían la mayor parte de los diezmos. Pero aquí nos interesa reflejar que esas mismas instituciones (Monasterio de San Millán de la Cogolla, Santa María la Real de Nájera, La Estrella; Conventos de Madre de Dios de Logroño o Santa María de Herce y Hospitales de Santo Domingo de la Calzada o el de Nájera) además se beneficiaban de alguna proporción de la cilla a la hora de los repartos. Por ejemplo, el Monasterio de San Millán llevaba la totalidad de los diezmos de Cárdenas y Cihuri y compartía los diezmos de Camprovín con el Convento de Madre de Dios. El diezmo que gozaban conventos y monasterios era el 6,3\% del total. Se caracterizaba por estar muy localizado, en unas diez villas, y suponía la casi totalidad de lo diezmado en ellas.

El otro pequeño grupo de beneficiarios de los diezmos eran los arciprestes (de Rioja, Calahorra, Logroño e incluso Briviesca o Valpuesta) y arcedianos (Logroño y Calahorra sobre todo), quienes se repartían casi por mitad un 3\% del diezmo. Aunque en el siglo XVI y comienzos del XVII su participación era proporcional al monto total, con el tiempo, estos derechos se convirtieron en rentas fijas que se esparcían en muy pequeñas cantidades por casi todos los municipios (en el 50\%), estando más implantado el arcediano que el arcipreste. Esto no es óbice para que, por ejemplo, en Cellorigo, el Arcediano de Valpuesta llevase la tercera parte del trigo y cebada. Lo frecuente fue tan sólo tener en propiedad unas pocas fanegas de trigo y cebada (casi en exclusiva los únicos cereales con los que se pagaban) que no excedían de las 30.

En resumen, haciendo una lectura a grandes rasgos, y creemos que más acertada, podemos decir que los diezmos en La Rioja se destinaban entre el 5 y el10\% para solventar los gastos de su recolección y primer almacenaje; algo menos de otro 10\% era aprovechado por los señores jurisdiccionales (a través de títulos de propiedad o arrendando las Tercias Reales) y el resto, un $80 \%$ por la Iglesia. Dentro de la iglesia un $10 \%$ lo percibía el clero secular (monasterios, conventos) y otro porcentaje similar los arcedianos, arciprestes, fábricas y sacristanes; un 17\% el Obispo y Mesas Catedralicias y el resto, un $43 \%{ }^{100}$, curas (rectores) y beneficiados (cabildos).

Por lo tanto, en esta región, a diferencia de Segovia los beneficiados percibían un porcentaje muy elevado (en Segovia un 2,8\%). Con los datos de los que disponemos pensamos que lo destinado a los curas (un 24\% en Segovia) era proporcionalmente menor en La Rioja. Así mismo, el Obispo y las Catedrales llevaban un porcentaje menor en la Diócesis calagurritana que en la segoviana (un 34,8\%). En esta última, era mayor lo obtenido por los señores jurisdiccionales, particulares y por las tercias

100. Reduzco considerablemente esta cantidad porque en los repartos, una vez entregadas unas escasas sacas, se le daba al Obispo y Catedrales su porcentaje y el resto de beneficiarios del diezmo lo eran en detrimento de los Cabildos y Beneficiados. 
(un 18,2\%) ${ }^{101}$. Las causas de todo ello, además de por la natural diversidad del si stema decimal, se deberían buscar en la composición del clero (en la Diócesis de Calahorra y, por tanto en La Rioja, proliferaba el clero patrimonial que accedía a su cargo con unas rentas) y en cuestiones políticas: La Rioja siempre fue frontera que interesó al Obispo y a la monarquía en dotarla de importantes centros religiosos capaces de contrarrestar el dominio de otros reinos (en la Edad Media y Moderna) y de hacer frente a las ideas extranjeras a través del País Vasco (establecimiento del Tribunal de la Inquisición en Logroño).

Por último, cabe preguntarse ahora por el destino final de ese diezmo. Es claro que únicamente los señores, el Obispo, los cabildos de cada lugar y los cabildos Catedralicios obtenían rentas lo suficientemente importantes como para destinarlas al comercio. Sin duda alguna el resto de beneficiarios íntegramente lo destinarían a su manutención o a los gastos ocasionados por su oficio. El Obispo y las Catedrales, donde el número de individuos entre quienes se debía repartir era reducido, eran los más favorecidos, en cambio los cabildos de las villas, más numerosos, debían destinar una parte al culto y a su manutención.

\section{PROBLEMAS ENTRE LOS PERCEPTORES DEL DIEZMO}

Los beneficiarios del diezmo siempre pretendieron aumentar su participación en la masa decimal y lo hicieron incluso comprando tierras y diezmos como se denunciaba en las Constituciones Sinodales ${ }^{102}$.

La propiedad de los diezmos enfrentó en muchos casos a las partes interesadas. La Mitra y Cabildo de Santo Domingo de la Calzada logró del Monasterio de San Millán de la Cogolla, después de no largos y costosos pleitos, que se le reconociesen como suyos y de las Iglesias Parroquiales Unidas de las Villas de Estollo, Berceo y San Andrés del Valle de San Millán, los diezmos mayores y menores de las heredades sitas en sus territorios campaniles y de los ganados laníos que en ellos se habían apacentado y apacentaban, junto con la mitad de los diezmos de los ganados de los vecinos de la villa de San Millán que pastasen en el custerio de las Unidas además de otras pormenorizaciones ${ }^{103}$.

Dentro de los custerios redondos de un dezmatorio podían presentarse términos diezmeros adscritos a otras parroquias ajenas a la natural. Debido a la primitiva existencia de iglesias como la de de San Juan de Atayo o Santa Fe de Palazuelos los términos campaniles de Lardero, en el primer caso, y Clavijo, en el segundo, se encontraban divididos en cuestiones de diezmos entre las parroquias de esas villas y la Colegial de Albelda y Logroño.

101. GARCÍA SÁNZ, A. 1977: 313-318. Y del mismo, 1975: 143-152.

102. C.S., 1700: 479-481.

103. A.P.Sant. leg. 1, f. 31. 
Sobre estos términos redondos inscritos dentro de otros, la jurisdicción decimal se encontraba muy diluida, más cuando ya no existían, como tales, las parroquias primitivas, como ocurría en ejemplos citados. Ahora los cultivadores eran parroquianos de una nueva iglesia ajena a aquellas y por tanto sus diezmos debían ser repartidos por mitad entre ambas. Así se nos dice que, en Palazuelos, eran los vecinos de Albelda los que sembraban pero por estar lejos lo abandonaron y eran los de Clavijo quienes lo hacían. Incluso recaudaban tales diezmos los hórreos de las nuevas parroquias, Clavijo y Lardero, y ellas se encargaban de repartir a sus poseedores la porción que les correspondía ${ }^{104}$.

En algunos lugares debido a que diezmo y primicia se recogían en un único montón o el parroquiano, que contribuía con ellos, era ajeno a la parroquia que tenía los derechos sobre las tierras que cultivaba, la distribución entre los interesados del diezmo debía hacerse en fracciones ya estipuladas por las partes, fracciones que podían variar con el tiempo ${ }^{105}$.

Otro tanto ocurría cuando desaparecía alguna villa. Los cabildos de las circunvecinas pretendían para sí los diezmos de sus tierras. A mediados del siglo XVII pleitearon la Colegial de Albelda y la Redonda contra el Cabildo de Entrena para dirimir dónde debían diezmar quienes cultivaban la tierra de la antigua villa de Velilla de la Rad. Debido a que Velilla había sido una de las Siete Villas del Campo con jurisdicción, aprovechamientos y pastos comunes, la disputa se decantó hacia Entrena, que también pertenecía a las Siete Villas. Mientras que Albelda tan sólo se podía llevar parte el diezmo, como era norma $1 / 20$, de sus parroquianos que labrasen en Velilla ${ }^{106}$.

En otros casos algún beneficiario de los diezmos eximía al resto de interesados de entregarle ciertos diezmos del hórreo común. Esto ocurría sobre todo entre el Obispo y los Cabildos de ciertas villas por ser poca cantidad lo que le correspondía al primero en la partición, o como contraprestación por unos servicios: por ejemplo, a cambio de no contribuir en los costos derivados de la construcción de un hórreo y unos lagos la Mesa Capitular de Calahorra eximió a los Beneficiados de Laguardia de entregar la cuarta parte del diezmo de pollos, lechones, ansarones, potros, becerros, otras aves y animales y de todo género de fruta, hortaliza y legumbres ${ }^{108}$.

104. A.P.Red. $\mathrm{n}^{\circ} 1.854$ y según los libros de tazmías. Nótese que la proporción de diezmo que hacen, $5 / 8$, no es la justa y que pueda deberse a que en esa cifra se incluye el diezmo de Palazuelos que le corresponde al propio Deán.

105. Ver, por ejemplo, el Caso de Atayo y Palazuelos: A.P.Red. Libro de cuentas y razón de la hacienda, rentas y diezmos de la mesa capitular de las iglesias colegiales de S. Martín de Albelda y Sta María de la Redonda de la ciudad de Logroño, 1614. A.P.Red. 1.854 (1627) y A.P.Red. $\mathrm{n}^{\circ} 2.223$

106. A.P.Red. $\mathrm{n}^{\circ} 2.155$ (3-X-1651). Solamente los diezmos del término "el Rubio" (¿entre Albelda y Velilla?) iban a parar al Cabildo de Albelda de los diezmantes de Velilla y Entrena.

107. En concordia de 1741 se exime al cabildo de Briñas de entregar los pollos a Calahorra por ser muy poco lo que se da, A.C.C. Lb. 265, fs. 52 y ss.

108. A.C.C. Lb. 265 , fs. 40 y ss. (1552). 
Más frecuente era que la Dignidad Episcopal o las Mesas Catedralicias viesen disminuir sus participaciones en los hórreos ${ }^{109}$. Para contrarrestar estos fraudes se acordaban infinidad de concordias. A través de ellas se establecía qué diezmos se producían en cada localidad, se regulaba cómo se debían diezmar, dónde debían ser entregados, que sacas se podían realizar, qué derechos tenía cada parte en su percepción, los gastos que se ocasionaban en la percepción y el reparto, cómo se debía contribuir en dichos gastos, quién elegía a los mayordomos, y un largo etcétera ${ }^{110}$. En este sentido, las concordias eran realmente una transcripción de las Constituciones Sinodales del Obispado junto con la regulación de las particularidades locales.

La casi totalidad de las concordias entre el Obispo y las villas aparecen re gistradas en el Libro que esta Santa Iglesia de Calahorra tiene hechas con los curas y beneficiados de los lugares infrascriptos, donde tiene tercios las Mesas Capitulares, de Común y Aniversarios. Es de notar que la mayoría de ellas se pactaron en la segunda mitad del XVII y comienzos del XVIII, es decir, en los últimos contratos de arrendamiento de los tercios obispales:

«Reconociendo comprehensivamente, por repetidas experiencias, y muy frecuentes noticias recibidas de personas muy temerosas de Dios, y como tales fidedignas, que de el arrendar los prestamos, tercios y cuartos decimales, y Beneficios, por años determinados, resulta muchas veces el que los arrendadores, por ser temporal su interés y por el miedo de seguir pleitos y gastar cantidad de maravedís en ellos, ceden del derecho que tienen a especies y cantidades de frutos, por razón de su arrendamiento, contentándose con aquello que voluntariamente quieren darles los partidores de los Diezmos. Todo lo cual es en conocido perjuicio de los propietarios, que insensiblemente y sin noticia de ello, vienen por este camino a perder los derechos que a los Diezmos tienen y se minoran notablemente sus piezas decimales. Y para que nadie en esto sea agraviado y se conserve a cada uno su derecho con indemnidad, Ordenamos y mandamos, S.S.A. que la negligencia y descuido, o poco animo de los arrendadores de frutos, no pueda parar, ni pare perjuicio a los propietarios de prestamos y Beneficios... por lo que se anulan y revocan todos los derechos que se puedan alegar que limiten la propiedad de los Diezmos a sus legítimos perceptores y ello se entienda incluso cuando los diezmos se cedieron en arrendamiento»"${ }^{11}$.

No sólo se limitaba la participación en el diezmo sino que de algunos productos se le excluía en el reparto. Este es el caso de las vinazas. El Obispo exigía que se le

109. Al Obispo, por su dignidad, le correspondían los diezmos de Arnedo y sus aldeas desde 1223, por donación del Obispo D. Juan y, como usufructuario de los mismos, mandaba quién cuidase y velase por ellos así como de recogerlos y partirlos indicando expresamente que no lo hiciesen los curas del lugar (Existían sentencias reafirmatorias de su posesión en 1668 y 1758, entre otras. La sentencia sobre los curas es de 1510. A.C.C. Lb. 232, f. 2). También le correspondían parte de los diezmos de Quel desde 1198; los de Ausejo, desde 1178; la tercera parte de los de Alcanadre, entregados por los Hermanos del Templo de Jerusalén al Obispo D. Rodrigo en 1155. Herramélluri tuvo pleitos en 1580 y 1667 con el obispo por el impago de toda la cuarta parte de los diezmos que le correspondía al Obispo. A.C.C. Lbs. 230, 232 y 233.

110. Algunos ejemplos: Agoncillo, 6-VII-1664; 1728. Alberite, 29-XII-1641; 24-IV-1664; 1666. Ausejo, 19-V-1664; 18-IV-1728. Autol, 1667(?); 19-VII-1717; 1748. Briñas, 26-II-1683; 8-II-1689; 31-X-1741. Clavijo, 25-II-1661. Labastida, 26-V-1689; 1769. Laguardia, agosto de 1552. Navarrete, 4-XI-1691; 23-IV1708. Quel, 17-VII-1664; 14-II-1743. San Vicente de la Sonsierra, 16-V-1700. Villamediana, 28-XI-1705.

111. C.S., 1700: 477-478. 


\section{SANTIAGO IBÁÑEZ RODRÍGUEZ}

entregase el diezmo de todo el vino. Del vino de pié, traspié, lágrima, escorredura, prensa y de las vinazas:

«las vinazas después de exprimir y prensar y después de que no dejen nada de mosto y estén secas se han de entregar una tercera parte a la Santa Iglesia bien en dinero o especie» ${ }^{12}$.

En algunos lugares se especifica que han de ser exprimidas hasta que no quede nada de mosto y "ni puedan servir sino es para la lumbre"113. En otros, como Labastida o en la iglesia de Santiago el Real de Logroño, las vinazas eran exclusivamente de los Beneficiados y en ellas no tenía participación el Obispo ${ }^{114}$.

Debido a que las Tercias Reales estaban arrendadas, en algunos casos, no se gozaban directamente y se daban en usufructo a una de las partes para que las administrasen. El Condestable de Castilla llevaba de Casalarreina las tercias a cambio de 5.000 mrs. por lo que entre la Catedral de Santo Domingo y el Cabildo de la villa se acordó que se encargasen de ellas los beneficiados a cambio de que la cuarta parte de los frutos que llevaba Santo Domingo, se convirtiesen en un sexto y los beneficiarios entregasen esa cantidad a la catedral para enviársela al Condestable ${ }^{115}$.

112. A.C.C. Lb. 265: Autol, f. 7. Año 1717. Otros ejemplos sobre que se debe entregar al Obispo la parte que le corresponde de vinazas: A.C.C. lbs. 232/233, Fuenmayor (1694), f. 655. A.C.C. Lb. 265, Villamediana (1705), f. 14. Navarrete (1708), f. 36. Quel (1664), f. 10. Laguardia (1552), f. 40. Briñas (1689), f. 52. Agoncillo (1664), f. 65, donde se dió sentencia para que se diezmase las vinazas después de varios pleitos que luego se continuarían en 1728. Quel (1717), f. 7.

113. A.C.C. Lb. 265, San Vicente de la S. f. 44.

114. A.C.C. Lb. 265, Labastida (1689), f. 97. A.P.Sant. leg. 6, tazmías.

115. A.H.D.Lo. Casalarreina, c. 19. 


\section{BIBLIOGRAFIA}

ÁLVAREZ VÁZQUEZ, J.A. 1984

Los diezmos en Zamora (1500-1840), Salamanca.

ARTOLA GALLEGO, M. 1978

La burguesía revolucionaria (1808-1874), Madrid.

ATIENZA LÓPEZ, A. 1988

Propiedad, explotación y rentas: el clero regular zaragozano en el siglo XVIII, Zaragoza.

CANALES, E. 1982

"Los diezmos en su etapa final": La economía española a fines del siglo XIX: I-Agricultura, ed. Anes, G., Madrid, 105-187.

CANALES, E. 1985

"Diezmo y revolución burguesa en España": Historia Agraria de la España Contemporánea: I-Cambio social y nuevas formas de propiedad (1800-1850), eds. García Sanz y Garrabou, R., Barcelona, 245-274.

CANGA ARGÜELLES, J., 1833

Diccionario de Hacienda, con aplicación a España, Madrid.

GARCÍA SÁNZ, A. 1975

"Los diezmos del Obispado de Segovia del siglo XV al XIX. Problemas de método, modos de percepción y regímenes sucesivos de explotación": I Jornadas de Metodología aplicada a las Ciencias Históricas, t. III, Santiago de Compostela, 143-152.

GARCÍA SÁNZ, A. 1977

Desarrollo y crisis del Antiguo Régimen en Castilla la Vieja. Economía y Sociedad en tierras de Segovia, Madrid.

GOUBERT, P. 1984

El Antiguo Régimen, Madrid.

LLORENTE, J.A. (presbítero), 1789

Discursos Histórico-Canónicos sobre los Beneficios Patrimoniales de las Iglesias Parroquiales del Obispado de Calahorra y La Calzada.

MARCOS MARTÍN, A. 1983

"De nuevo sobre los diezmos. La documentación decimal de la diócesis de Palencia: problemas que plantea": Investigaciones Históricas 4, 101-122. 


\section{MARTÍN RODRÍGUEZ, J.L. 1975}

"Diezmos eclesiásticos: notas para la economìa de la sede zamorana (siglos XIIXIII)", Actas de las I Jornadas de Metodología aplicada a las Ciencias Históricas. II, Santiago de Compostela, 69-78.

Constituciones sinodales de la diócesis de Calahorra y la Calzada, 1553, del obispo D. Juan Bernal de Luco, Logroño. [citado como C.S., 1553]

Constituciones sinodales de la diócesis de Calahorra y la Calzada, 1602, del obispo D. Pedro Manso de Zúñiga, Logroño. [citado como C.S., 1602]

Constituciones sinodales de la diócesis de Calahorra y la Calzada, 1620, del obispo D. Pedro González del Castillo, Logroño. [citado como C.S., 1620]

Constituciones sinodales de la diócesis de Calahorra y la Calzada, 1700, del obispo D. Pedro de Lepe, Madrid. [citado como C.S., 1700] 